San Jose State University

SJSU ScholarWorks

Master's Theses

Master's Theses and Graduate Research

1990

\title{
Thermal cycling effects on polyimide films for multilayer applications
}

Stacey T. Baba

San Jose State University

Follow this and additional works at: https://scholarworks.sjsu.edu/etd_theses

\section{Recommended Citation}

Baba, Stacey T., "Thermal cycling effects on polyimide films for multilayer applications" (1990). Master's Theses. 35.

DOI: https://doi.org/10.31979/etd.zvup-87eu

https://scholarworks.sjsu.edu/etd_theses/35

This Thesis is brought to you for free and open access by the Master's Theses and Graduate Research at SJSU ScholarWorks. It has been accepted for inclusion in Master's Theses by an authorized administrator of SJSU ScholarWorks. For more information, please contact scholarworks@sjsu.edu. 


\section{INFORMATION TO USERS}

The most advanced technology has been used to photograph and reproduce this manuscript from the microfilm master. UMI films the text directly from the original or copy submitted. Thus, some thesis and dissertation copies are in typewriter face, while others may be from any type of computer printer.

The quality of this reproduction is dependent upon the quality of the copy submitted. Broken or indistinct print, colored or poor quality illustrations and photographs, print bleedthrough, substandard margins, and improper alignment can adversely affect reproduction.

In the unlikely event that the author did not send UMI a complete manuscript and there are missing pages, these will be noted. Also, if unauthorized copyright material had to be removed, a note will indicate the deletion.

Oversize materials (e.g., maps, drawings, charts) are reproduced by sectioning the original, beginning at the upper left-hand corner and continuing from left to right in equal sections with small overlaps. Each original is also photographed in one exposure and is included in reduced form at the back of the book.

Photographs included in the original manuscript have been reproduced

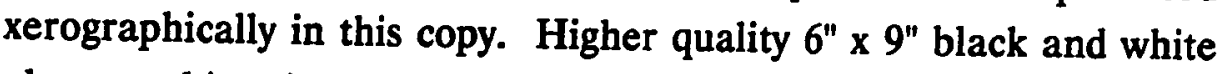
photographic prints are available for any photographs or illustrations appearing in this copy for an additional charge. Contact UMI directly to order.

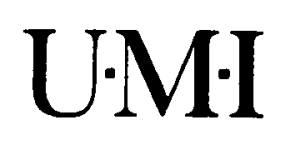

University Microfilms International

A Bell \& Howell Information Company

300 North Zeeb Road, Ann Arbor. MI 48106-1346 USA

$313 / 761-4700 \quad 800 / 521-0600$ 

Thermal cycling effects on polyimide films for multilayer applications

Baba, Stacey T., M.S.

San Jose State University, 1990 


\author{
A Thesis \\ Presented to \\ The Faculty of the Department of Materials Engineering \\ San Jose State University
}

\author{
In Partial Fulfillment \\ of the Requirements for the Degree \\ Master of Science
}

By

Stacey T. Baba

December, 1990 
APPROVED FOR THE DEPARTMENT OF MATERIALS ENGINEERING

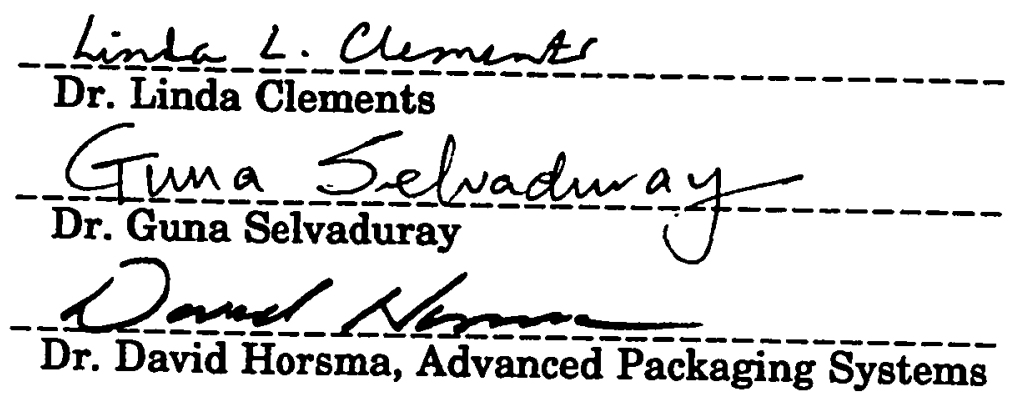

APPROVED FOR THE UNIVERSITY M. Lon Lewrendoweri 


\begin{abstract}
THERMAL CYCLING EFFECTS ON POLYIMIDE FILMS FOR MULTILAYER APPLICATIONS

by Stacey T. Baba
\end{abstract}

This thesis examines the thermal cycling effects on polyimide isoindoloquinazolinedione (PIQ) films for multilayer applications. The densification phenomenon and changes in storage modulus, $\tan \partial$ and glass transition temperatures which had been previously observed in pyromellitic dianhydride-oxydianaline polyimide (PMDA-ODA) were examined. Three diverse methods were used to examine the PIQ film. No increase occurred in the refractive index measurements for films cycled five times above $400^{\circ} \mathrm{C}$. No decrease occurred in contact angle measurements for films cycled ten times above $400^{\circ} \mathrm{C}$. No change was measured by dynamic mechanical analysis in the glass transition temperature or $\tan \partial$ of films cycled five times above $400^{\circ} \mathrm{C}$.

PIQ does not densify nor do mechanical properties change due to thermal cycling. Review of the molecular structure reveals substantial differences between PIQ and PMDA-ODA. PIQ has a copolymer structure and an additional cyclic ring (quinazolinedione ring) which may aid in its thermal stability. 


\section{ACKNOWLEDGEMENTS}

This thesis is the final chapter of what has been an extremely long story that started almost ten years ago. Although only a small fraction can be mentioned, I would like to thank all of the people who have lent support and feedback during these many years. Without their encouragement, I would not be writing this thesis.

I would first like to thank my sponsor, Advanced Packaging Systems, for their financial support for this work and the president of APS, Richard Otte, for his encouragement. I would also like to acknowledge my industrial sponsor, Dr. David Horsma, for his technical guidance and his good common sense.

Next, I would like to thank the faculty and staff at San Jose State University. The first, of course, is my graduate advisor, Prof. Linda Clements, who has been kind enough to shepherd me through all the trials and tribulations of the valley of the "part time student." I would like to thank Prof. Burt Masters for his encouragement and advice during my oral examination. I would also like to thank Prof. Guna Selvaduray, the chair of my committee, who has provided me a great deal of guidance and taken care of a lot of the paperwork.

I would also like to thank my friends and coworkers at Raychem Corporation who helped characterize the materials in this research. I would like to acknowledge, Dr. Steven Moore and Gloria Merlino in the Physical Test Lab and Tony Idem in Materials Quality Control.

I would like to thank my parents for their encouragement and enthusiasm. 
Finally, I would like to thank my husband for his love, support and encouragement. He always said I would finish. 


\section{TABLE OF CONTENTS}

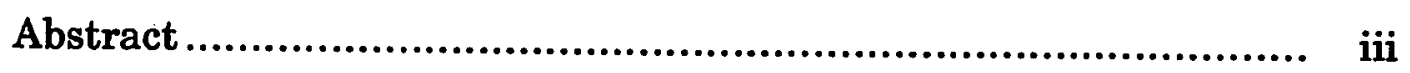

Acknowledgment ........................................................ iv

Table of Contents....................................................... vi

List of Figures......................................................... viii

List of Tables................................................................ ix

List of Abbreviations ..................................................... $\quad x$

Chapter One. Introduction ................................................. 1

Background of the Issue............................................... 1

Synthesis and Processing of Polyimides ............................... 4

Previous Structural Studies of PMDA-ODA at Elevated

Temperatures.......................................................... 5

Research Objective ................................................. 10

Outline of Thesis .................................................... 12

Limitations of this Research......................................... 13

Chapter Two. Film Preparation and Measurement..................... 14

Thin Film Fabrication ................................................ 14

Chapter Three. Thermogravimetric Analysis (TGA) .................. 19

Thermogravimetric Analysis ....................................... 19

Isothermal Weight Loss Analysis ................................. 19

Thermogravimetric Analysis Results.............................. 20

Chapter Four. Refractive Index Measurements ........................ 23 
Refractive Index Measurements ................................... 26

Results for Refractive Index Measurements....................... 26

Chapter Five. Contact Angle Measurements ............................ 28

Young's Equation and Contact Angle Measurements............. 28

Contact Angle Measurements ....................................... 30

Results for Contact Angle Measurement............................ 31

Chapter Six. Dynamic Mechanical Analysis (DMA).................... 35

Dynamic Mechanical Analysis ....................................... 35

Results for DMA …................................................... 37

Chapter Seven. Summary and Conclusions............................. 41

Review of the Problem............................................... 41

Discussion of the Findings .......................................... 41

Conclusions......................................................... 42

Recommendations for Future Actions ............................... 43

References............................................................. 44

Bibliography ......................................................... 47

Appendix 1. Hitachi Chemical Company's recommended imidization process for PIQ in a convection oven ................... 48

Appendix 2. TGA Results ............................................... 49

Appendix 3. Snell's Law................................................... $\quad 52$

Appendix 4. Error calculation in application of density and refractive index relationship........................................... 53 


\section{LIST OF FIGURES}

Figure 1. Typical multilayer dielectric structure ...................... 3

Figure 2. Reaction between pyromellitic dianhydride (PMDA) and oxydianaline (ODA) to form PMDA-ODA polyimide

Figure 3. The structure of monomer $\mathbf{n}$ of polyimide isoindoloquinazolinedione (PIQ)

Figure 4. The structure of monomer $m$ of polyimide isoindoloquinazolinedione (PIQ)

Figure 5. Illustration of potential ladder structure between PIQ molecules.

Figure 6. Process sequence used to make polyimide film ........... 15

Figure 7. Schematic of a prism coupler ............................... 24

Figure 8. Change in refractive index measurements as a function of thermal cycles................................... $\quad 27$

Figure 9. Illustration of Young's equation............................ 29

Figure 10. Schematics of contact angle goniometer.................... 32

Figure 11. Change in contact angle measurements as a function of thermal cycles.................................. 33

Figure 12. Glass transition data from dynamic mechanical analysis.

Figure 13. Tan $\partial$ data from dynamic mechanical analysis.......... 40

Figure 14. Hitachi Chemical's recommended imidization process.

Figure 15. Mlustration of Snell's law 


\section{LIST OF TABLES}

Table 1. Basic properties of polyimides......................................... 2

Table 2. Summary of test methods and film thicknesses and configurations studied in this investigation.................. 18

Table 3. Results from Thermogravimetric Analysis....................... 22 


\section{LIST OF ABBREVIATIONS}

$\begin{array}{ll}\text { APS } & \text { Advanced Packaging Systems } \\ \text { DMA } & \text { Dynamic Mechanical Analysis } \\ \text { NMP } & \text { N-methyl pyrollidone } \\ \text { ODA } & \text { oxydianaline } \\ \text { PIQ } & \text { polyimide isoindoloquinazolinedione } \\ \text { PMDA } & \text { pyromellitic dianhydride } \\ \text { PMDA-ODA } & \text { pyromellitic dianhydride- oxydianaline } \\ \text { Tg } & \text { glass transition temperature } \\ \text { TGA } & \text { Thermogravimetric Analysis } \\ \text { VLSI } & \text { Very Large Scale Integration }\end{array}$




\section{CHAPTER ONE}

\section{INTRODUCTION}

\section{Background of the Issue}

The importance of polyimides as an interlayer dielectric for Very Large Scale Integration (VLSI) technology has been well documented [1-6]. Polyimides are popular due to their good electrical, environmental and physical performance characteristics, ability to planarize features, resistance to process chemicals and temperatures and their widespread commercial availability. Some of the basic properties of polyimides which make them popular for this technology are shown in Table 1. Most recently, polyimides have become very popular as the dielectric for multichip modules. A typical structure for this module, shown in Figure 1, consists of alternating layers of polyimide dielectric layers and metal layers, repeated multiple times. Devices with as many as six dielectric layers have been reported [7]. In each case, when the polyimide is used as the dielectric, it is heated to high temperatures above its glass transition temperature as part of the imidization or curing reaction. This means that as successive layers of polyimide are processed, the lower layers of polyimide are exposed to repeated thermal cycles. Questions arise with regard to the thermal stability of the polyimide and changes in the morphology of the polyimide film. Changes in the film could affect the module's performance and reliability.

This thesis describes the changes in a polyimide film subjected to multiple thermal cycles. The research was completed in the context of using the polyimide in multilayer application such as the dielectric for multichip modules. In Chapter One the synthesis and processing of two 
Table 1. Basic properties of polyimides [3]

\begin{tabular}{|c|c|}
\hline Property & Value \\
\hline \multicolumn{2}{|l|}{ Electrical } \\
\hline Dielectric Constant & $2.8-4.0$ at $1.0 \mathrm{kHz}$ \\
\hline Dissipation Factor & 0.002 at $1.0 \mathrm{kHz}$ \\
\hline Dielectric Strength & $>100 \mathrm{kV} / \mathrm{mm}$ \\
\hline Volume Resistivity & $1.0 \times 10 \mathrm{e} 14$ to $1.0 \times 10 \mathrm{e} 16 \mathrm{ohm}-\mathrm{cm}$ \\
\hline \multicolumn{2}{|l|}{ Thermal } \\
\hline Thermal Decomposition Temperature & $450^{\circ} \mathrm{C}$ to $650^{\circ} \mathrm{C}$ \\
\hline Glass Transition Temperature & $200^{\circ} \mathrm{C}$ to $>400^{\circ} \mathrm{C}$ \\
\hline Thermal Expansion Coefficient & $2 \times 10 \mathrm{e}-6$ to $1 \times 10 \mathrm{e}-4 \mathrm{~cm} / \mathrm{cm}^{\circ} \mathrm{C}$ \\
\hline Thermal Conductivity at $25^{\circ} \mathrm{C}$ & $0.16 \mathrm{~W} / \mathrm{m}^{\circ} \mathrm{K}$ \\
\hline \multicolumn{2}{|l|}{ Mechanical } \\
\hline Tensile Strength & 90 to $300 \mathrm{MPa}$ \\
\hline Tensile Modulus & 1.3 to $6.2 \mathrm{GPa}$ \\
\hline Elongation & 5 to $100 \%$ \\
\hline Color & Clear to light brown \\
\hline Moisture Absorotion & 1 to $5 \%$ \\
\hline
\end{tabular}




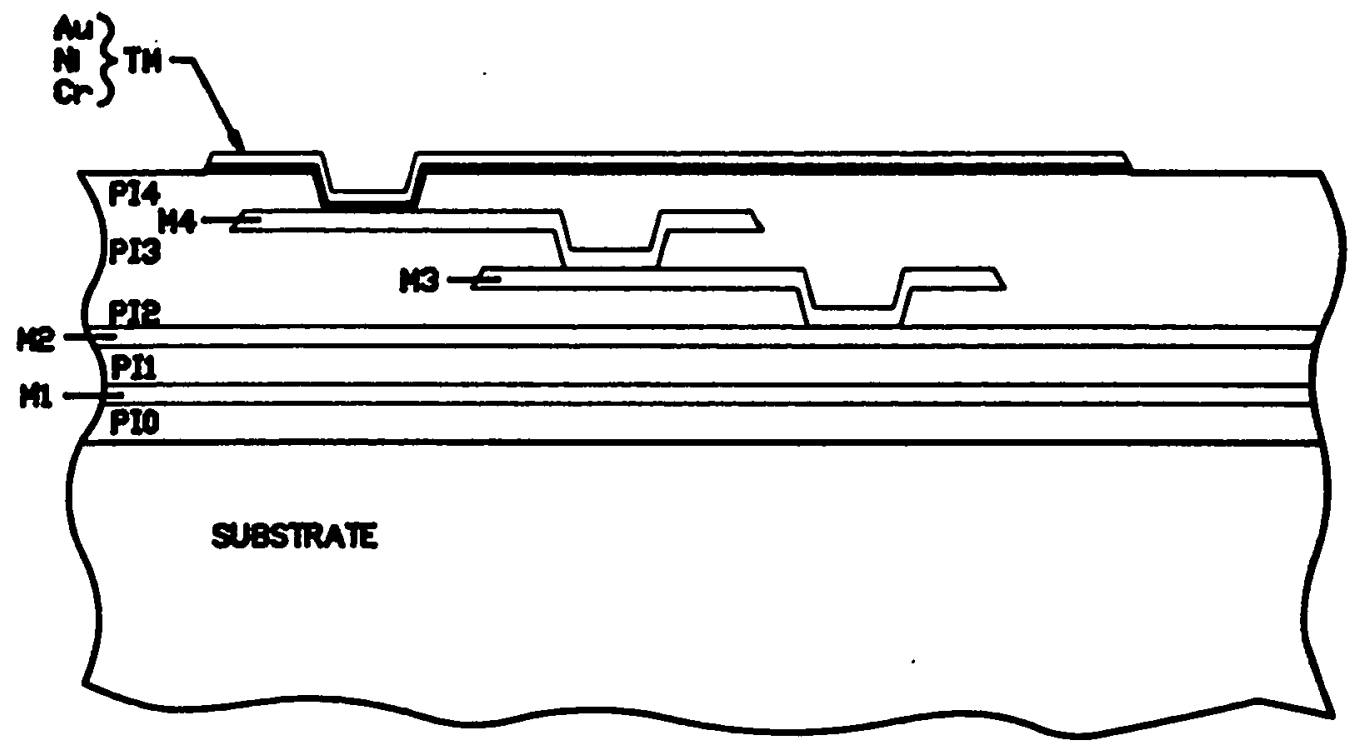

Figure 1. Typical multilayer dielectric structure [8]. 
commercial polyimides are described, previous studies of PMDA-ODA polyimide at elevated temperatures are reviewed, the research objective is stated and limitations are discussed.

\section{Synthesis and Processing of Polvimides}

Polyimides belong to the class of organic polymers. Most polyimides used in the microelectronics industry are aromatic (derivative of benzene) polyimides because these have the highest strength and thermal stability [9]. The "standard" polyimide is derived from a diamine and a dianhydride which are reacted to form a poly(amic acid). For commercial applications, the poly(amic acid) is supplied in solution in a solvent such as $\mathrm{N}$-methyl pyrollidone (NMP). This solution is applied to the substrate by spin, spray or roller coating. It is then typically "softbaked" at low temperatures from $80^{\circ} \mathrm{C}$ to $200^{\circ} \mathrm{C}$ to remove moisture and solvents. Imidization will also begin. The polyamic acid is fully imidized (also referred to as "cured") into a polyimide by a final process at an elevated temperature, typically around $400^{\circ} \mathrm{C}$. This cure schedule will vary and is dependent upon the chemistry of the polyimide, the solvent system, and the equipment used. During this final step, water is produced, the remaining solvent is removed and the polyamic acid is fully converted into a polyimide. This final step is probably the most important part of the entire coating procedure because it will determine the extent of imidization. The ultimate electrical, chemical and physical properties of the polyimide are a function of the degree of imidization.

There are many commercially available polyimides. Du Pont, Ciba Geigy and Hitachi Chemicals are but a few of the companies that have 
developed polyimides for multilayer structures. One polyimide, developed by du Pont, is shown in Figure 2. This polyimide was one of the earliest developed for microelectronic applications. It is pyromellitic dianhydride-oxydianaline, and is commonly referred to as PMDA-ODA polyimide.

PMDA-ODA has been well characterized and these previous studies will be reviewed in the next section.

Another polyimide, developed by Hitachi Chemicals, is polyimide isoindoloquinazolinedione or PIQ. PIQ is actually a random copolymer. Monomer n, shown in Figure 3, resembles PMDA-ODA, and is derived from a diamine and a dianhydride. In addition to the monomer $n, P I Q$ also consists of a monomer $\mathrm{m}$, which after final imidization, forms an additional cyclic ring, identified as the quinazolinedione ring linkage as illustrated in Figure 4. Although the chemical compositions of the $R$ groups are considered proprietary, R1 and R3 have been identified as aromatic amines and $\mathrm{R} 2$ is an aromatic ring that comes in two forms $[10,11]$.

\section{Previous Structural Studies of PMDA-ODA at Elevated Temperatures}

Although the imidization reaction can be activated chemically, for most industry applications, a thermal process is used. In a multilayer polyimide construction, as each subsequent dielectric layer is formed and is imidized, the lower dielectric layers are thermally cycled. For a structure that has five layers as shown in Figure 1, the first layer is cycled at least four times during construction. Depending on the process, these temperature excursions can range from $350^{\circ} \mathrm{C}$ to $450^{\circ} \mathrm{C}$, which can be above the 
<smiles>Nc1ccc(Oc2ccc(N)cc2)cc1</smiles>

PMDA<smiles>CCCCCCCCCCCO</smiles><smiles>CCC(C)(CC)Nc1ccc(Oc2ccc(C)cc2)cc1</smiles>

Polyamic Acid<smiles>CCCCO</smiles><smiles></smiles>

Polyimide PMDA-ODA

Figure 2. Reaction between pyromellitic dianhydride (PMDA) and oxydianiline (ODA) to form PMDA-ODA polyimide. 

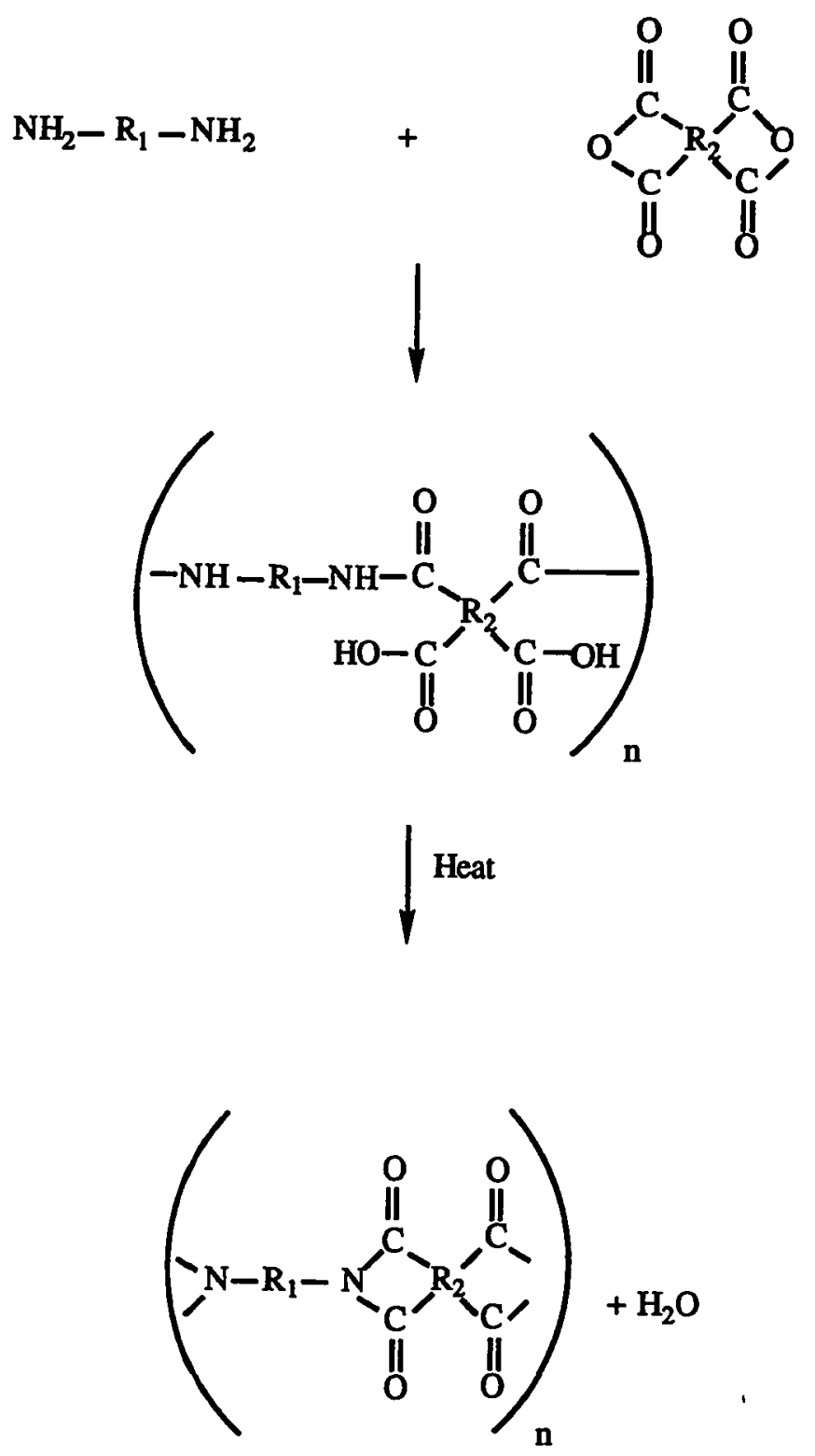

Figure 3. The structure of monomer $\mathbf{n}$ of polyimide isoindoloquinazolinedione (PIQ). R1 and R2 are proprietary aromatic structures [10]. 

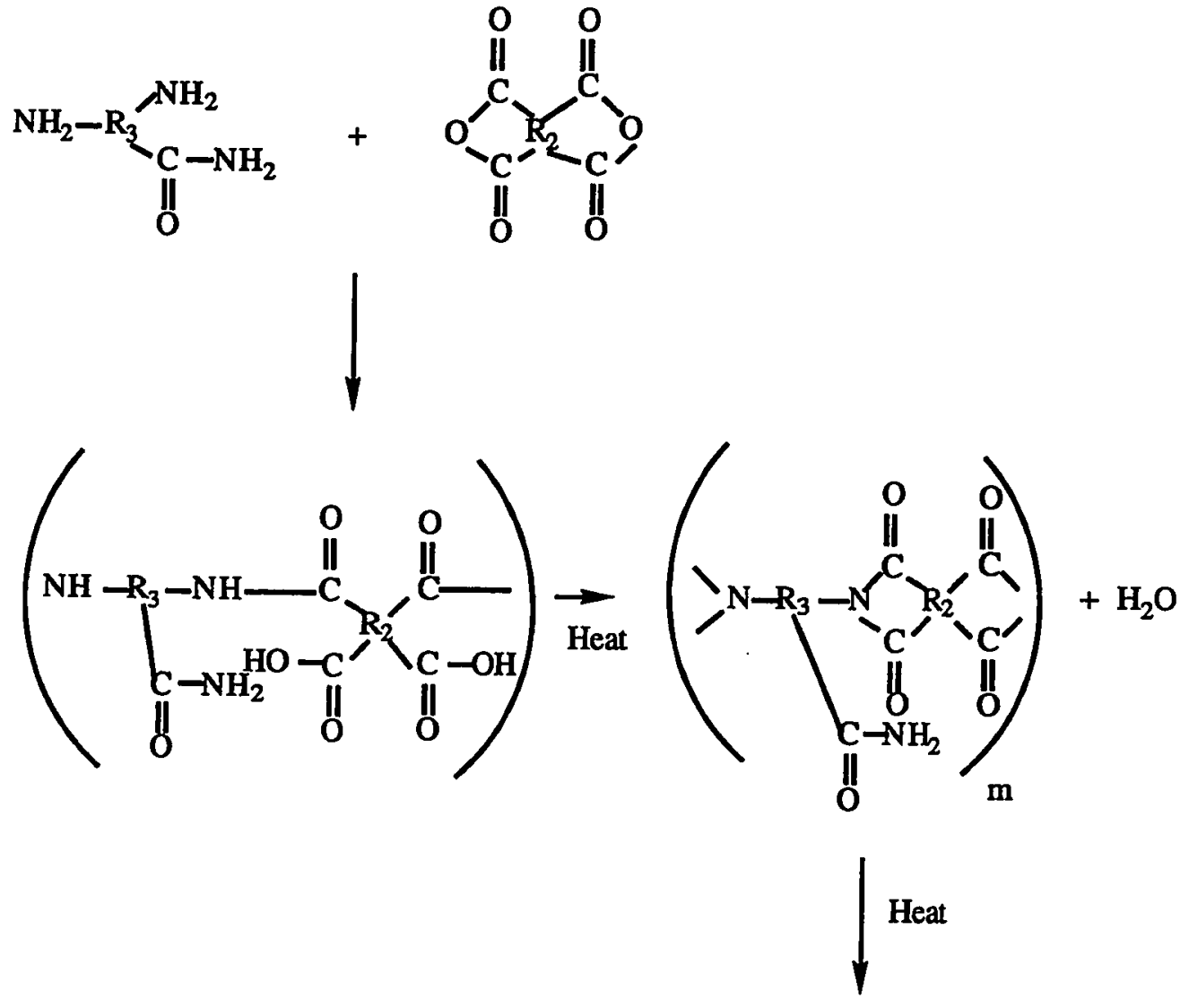

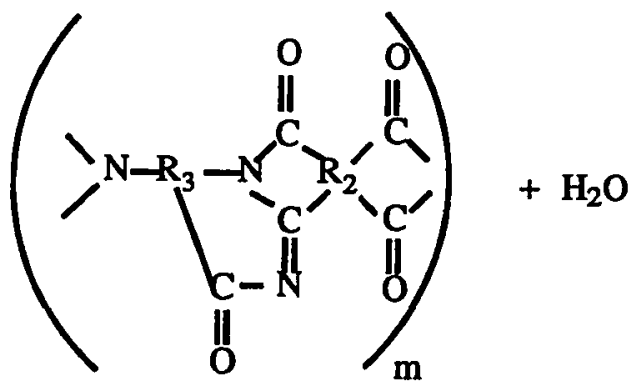

Figure 4. The structure of monomer $m$ of polyimide isoindoloquinazolinedione (PIQ). R2 and R3 are proprietary structures [10]. 
polyimide glass transition temperature $\left(\mathrm{T}_{\mathrm{g}}\right)$ [11]. Recently, there has been evidence that although the polyimide has been fully imidized, a change in the film's morphology will continue to occur when heated above the film's $\mathrm{T}_{\mathrm{g}}$. Studies by Russell [12] and Isoda [13], have shown that temperature cycling in this regime can cause short range ordering of the polymer chain. In Russell's study, he found an increase in the mass density of the PMDA-ODA film with an increase in the initial imidization temperature. He attributed this increase in density to the ordering or packing of the PMDA-ODA molecules. Takahashi [14], in his studies of polyimide, found ordered chain segments in the polyamic acid before imidization and also found that after the substrate was raised above the initial imidization temperatures, there was a preferred orientation of the chains along the film plane. He discovered that further improvement in ordering occurred upon annealing the polyimide films above $300^{\circ} \mathrm{C}$ but that no further ordering was observed above $350^{\circ} \mathrm{C}$. Feger's studies [15] showed that molecular packing or densification of the polyimide occurred at temperatures above $300^{\circ} \mathrm{C}$. Using dynamic mechanical thermal analysis, he found that as the film densified, an increase in the storage modulus occurred.

These previous studies investigated the densification of PMDA-ODA. PMDA-ODA polyimide was one of the earliest polyimides used for multilayer applications and has a linear structure which can densify during thermal cycling [16-17]. In comparison, the monomers shown in Figures 3 and 4, indicate that PIQ has a much more complex structure. It is a random copolymer, with the quinazolinedione ring linkage in its structure. The randomness and the extra ring may make it difficult for the polyimide to 
densify. However, scientists at Hitachi Chemicals suspect that densification could also occur in PIQ after repeat thermal cycles [10]. This hypothesis is based on their speculation that for the PIQ monomers occasionally the quinazolinedione ring may not form and instead a bond occurs between the amide (an organic group containing the $\mathrm{CO} \cdot \mathrm{NH}_{2}$ radical) and an adjacent carbonyl (the bivalent radical $\mathrm{CO}$ ) group. Over repeated thermal cycles, there is a possibility that a "ladder" network may be formed, as shown in Figure 5. The network would orient the PIQ polymer chains into a linear structure. The bonding between the amide and carbonyl group would pack the polymer chains together and densification would occur.

\section{Research Objective}

Previous studies have shown that densification and an increase in the elastic modulus of the PMDA-ODA polyimide occur after elevated heat treatment. Hitachi scientists hypothesize that a similar phenomenon may also occur in PIQ. It may seem unclear why densification is a concern. A correlation between densification and product failure has not been well defined. However, any change in materials used for a new technology should be clearly understood and characterized. For example, if the elastic modulus of the film is rising, what are the stresses that are occurring? Stresses in thin films could lead to problems such as crack sensitivity and adhesion failures. Do reactions continue during the repeated thermal cycles? Changes in the film morphology could affect the performance level in the film. Most of the data available for polyimide films used in multilayer applications have been obtained from single layer, single thermal cycle 

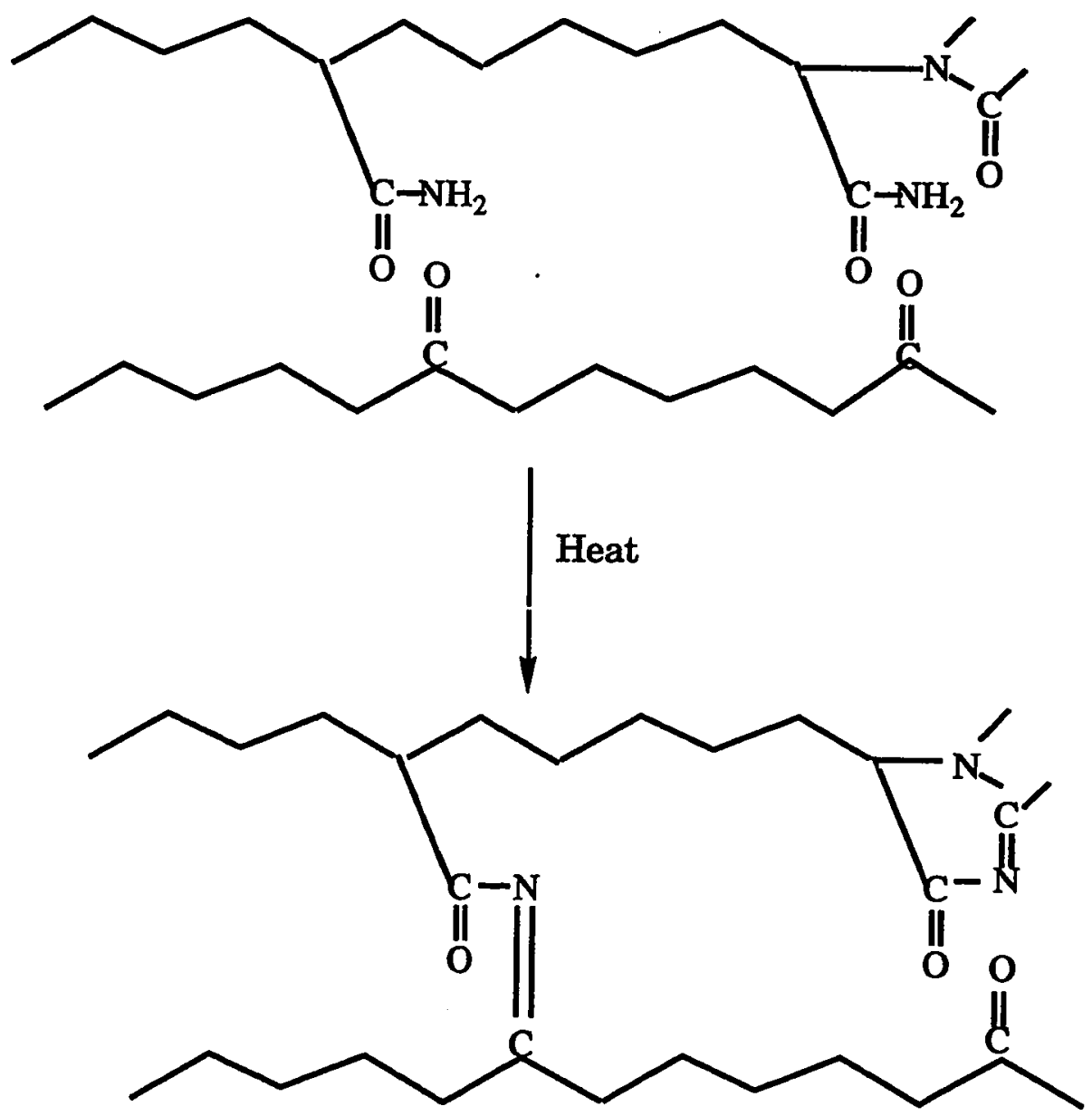

Figure 5. Mlustration of potential ladder structure between PIQ molecules [10 ]. 
films.

The author hypothesized that if similar changes in the PIQ polyimide film occur, then densification could be detected by measuring the film's refractive index or by measuring the film's contact angle. In addition, as a result of densification, changes in the storage modulus and shifts in the glass transition temperature could be detected by dynamic mechanical analysis (DMA).

In addition to this research objective, another goal of this study was to find a method to monitor the changes in the film in a production environment. This required that the methods used examine the polyimides in a film format.

\section{Qutline of Thesis}

Film preparation and configuration are discussed in Chapter Two. Different film thicknesses were required for the various studies used to examine the polyimide film.

The imidization process used by Advanced Packaging Systems (APS) is examined in Chapter Three, where the results of thermogravimetric analysis (TGA) are reported. Chapter Four reports the change in refractive index as a function of thermal cycles. In Chapter Five, the results of the contact angle measurements as a function of thermal cycles are discussed. In Chapter Six, PIQ is examined using dynamic mechanical analysis (DMA), and handling limitations are discussed.

Summary and conclusions appear in Chapter Seven. 


\section{Limitations of this Research}

When examining a material for a new technology it can become difficult to limit the scope of the study. Because one goal was to develop a monitoring method for production, the polyimide films were made on production equipment using production processes. This also required that the polyimide be studied in a film state or as close to the product state as possible.

Although the interest in this study is focused on those layers which have had multiple thermal cycles, these layers are also the buried layers in a multilayer structure. It would be difficult to do a direct analysis on these layers without disturbing the surface and potentially modifying the chemistry of this thin film. Therefore, single layer films were prepared, subjected to the thermal cycles and tested. A major assumption in the preparation of these films was that the multiple thermal cycles performed in the oven under a nitrogen blanket were similar to those experienced by buried polyimide layers. The inert environment of the oven would prevent oxidation to the surface. It is believed that this would be the major cause of any difference between a top layer and a buried layer. 
CHAPTER TWO

FILM PREPARATION AND MEASUREMENT

\section{Thin Film Fabrication}

All films were prepared by spin coating the polyamic acid/NMP solution onto a $125 \mathrm{~mm}$ silicon wafers, as shown in Figure 6. A commercial spin coater was used for this process. The substrate was rotated at a slow speed ranging from 100 to $500 \mathrm{rpm}$ and the polyamic acid was dispensed onto the wafer. The substrate was then rapidly accelerated, held at a constant speed (typically 1000 to $3000 \mathrm{rpm}$ ), and than rapidly decelerated. By controlling the spin speed and time, a uniform coating of the polyamic acid was obtained on the wafer. The coated wafer was "softbaked" on a hot plate in air. The softbake step removed NMP and began imidization. After the softbake process, the substrate was fully imidized in an oven in a nitrogen environment. Films made using this process were approximately $3.7 \mu \mathrm{m}$ thick.

A typical dielectric layer at Advanced Packaging Systems (APS) is approximately $11 \mu \mathrm{m}$. In order to obtain this thickness, the substrate is coated and softbaked three times, and then imidized. However, the $11 \mu \mathrm{m}$ films caused problems during the initial stages of this investigation. During previous studies [19] it was found that an $11 \mu \mathrm{m}$ film was too thick to obtain reproducible refractive index data. Thus, the films prepared for the refractive index measurements were $3.7 \mu \mathrm{m}$ thick. However, the opposite problem occurred during the DMA studies. The $11 \mu \mathrm{m}$ films were too difficult to handle because they were too thin. Because of this handling 
No coating present

Bare substrate

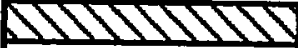

Room temperature process

Minimum solvent loss

Polyamic acid/solvent

"spun" onto substrate

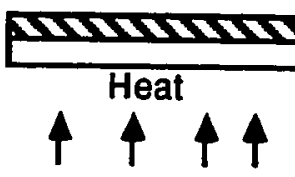

Processed at $<200 \mathrm{C}$

Up to $80 \%$ solvent loss

Imidization occuring

Ring closure occuring

Polyamic acid

"softbaked", some

solvent removal

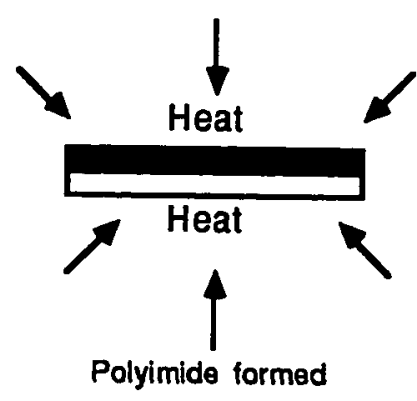

Processed at $>300 \mathrm{C}$

Removal of all solvent Imidization completed

Film at room temperature

Polyimide film finished

Film on substrate

Figure 6. Process sequence used to make a polyimide film [19]. 
issue, films prepared for the DMA were approximately $55 \mu \mathrm{m}$ thick. It was later learned that further modifications should have been made. A detailed description of the handling problems is given in Chapter 6. The $11 \mu \mathrm{m}$ films were suitable for the TGA and contact angle measurements and were used for these methods.

To obtain the various film thicknesses, the coat and softbake step was repeated multiple times in order to produce all but the $3.7 \mu \mathrm{m}$ films. As noted before, three coat and softbake steps were necessary to obtain the $11 \mu \mathrm{m}$ films. The $55 \mu \mathrm{m}$ films were obtained by coating and softbaking the wafer 15 times. Once the proper softbake thickness was obtained, the coated wafer was then imidized. As mentioned earlier, the imidization reaction is probably the most critical step in the coating process. In order to ensure a reproducible process, the oven temperature and time at temperature were monitored during this process. The imidization reaction was completed in an oven which was ramped to a final temperature of $400^{\circ} \mathrm{C}$ in a nitrogen atmosphere. The repeatability of the final temperature was within $\pm 5^{\circ} \mathrm{C}$. Because the imidization process at APS is proprietary the details cannot be disclosed. However, it is similar to the process that Hitachi Chemicals recommends, as detailed in Appendix 1.

The coated wafers which represented a single layer structure went through the imidization process or thermal cycle only once. Those that represented the bottom layer of a three layer structure went through this thermal cycle three times. Those that simulated the bottom layer of a five layer structure were thermally cycled five times. For the specimens that simulated a ten layer structure the substrate was thermally cycled ten 
times. After the final imidization cycle, the final film thickness was measured using a Nanospec AFT.

Free standing films were required for TGA and DMA. After thickness measurements were taken, the coated wafers were placed in a beaker of boiling water. After two to three hours, the polyimide film would float free of the substrate. The films were dried prior to storage. Previous calculations by Keeley [18] have shown that water will diffuse out of a $10 \mu \mathrm{m}$ film within a few seconds. To ensure that these films were free of residual moisture, they were placed on filter paper and dried in a convection oven at $125^{\circ} \mathrm{C}$ in air for two hours. Table 2 summarizes the film thickness and configuration and the methods used to study the PIQ film for this investigation. 
Table 2. Summary of test methods and film thickness and configuration studied in this investigation

\begin{tabular}{|c|c|c|}
\hline Test Method & $\begin{array}{l}\text { Film Thickness } \\
\qquad(\mu \mathrm{m})\end{array}$ & Free Standing \\
\hline Thermogravimetric Analysis (TGA) & 11.0 & yes \\
\hline Refractive Index Measurement & 3.7 & no \\
\hline Contact Angle Measurement & 11.0 & no \\
\hline Dynamic Mechanical Analysis (DMA) & 55.0 & yes \\
\hline
\end{tabular}




\section{CHAPTER THREE \\ THERMOGRAVIMETRIC ANALYSIS}

An early activity in this study was to establish that the polyimide films were fully imidized. Because the process used to imidize the films had been established internally at APS and was different than the process recommended by the vendor, it was necessary to confirm that the imidization reaction had occurred and was completed. This would eliminate the imidization reaction as a possible cause if changes were observed in the film. This chapter describes the technique used to determine the completeness of the imidization reaction and the results.

\section{Isothermal Weight Loss Analysis}

The analysis was conducted using a Perkin Elmer Thermal Gravimetric Analyzer, TGA 7. The data was calculated on a Perkin Elmer 7700 Professional Computer. The accuracy for this system is $\pm 5.0 \mu \mathrm{g}$ with a resolution of $\pm 0.5 \mu \mathrm{g}$. Thermogravimetric analysis (TGA) measures the change of weight of a substance as a function of temperature or time, and is a typical measurement of the polymer's stability. A loss in weight due to the liberation of water or NMP during isothermal measurements would indicate that the polyimide film was not fully imidized.

Two $11 \mu \mathrm{m}$ films were prepared as described in Chapter 2. The first film was "softbaked" only and did not go through the final imidization process. The second film was imidized once. Prior to test, the film was removed from the substrate. Each film was cut into 3 by $3 \mathrm{~mm}$ squares, 
placed in the test chamber and conditioned in a nitrogen environment at $100^{\circ} \mathrm{C}$ for 30 minutes to remove moisture from the film. The chamber was ramped at a rate of $20^{\circ} \mathrm{C} /$ minute to $300^{\circ} \mathrm{C}$ and held for 190 minutes. The loss of weight was measured. The selection of the test temperature was based on finding a temperature high enough to complete the imidization of the film within a short period, yet not so high as to degrade the film. At $300^{\circ} \mathrm{C}$, if the polyimide were not fully imidized, the imidization reaction would continue and water and NMP would be evolved. A loss of weight would clearly be evident. If the polyimide were fully imidized, the film would be thermally stable, and no loss of weight would occur. However, $300^{\circ} \mathrm{C}$ was well below the decomposition temperature of this material, and loss of weight due to degradation was never a concern [21].

\section{Thermogravimetric Analysis Results}

Although TGA measurement for polymers is a proven method, there was some difficulty in developing a technique to handle the thin films and small specimen sizes in the chamber. One difficulty encountered was that the instrumentation kept indicating a gain in weight in the film as the chamber was ramped from one temperature to another. This phenomenon was even exhibited by an empty chamber. Discussions with the equipment vendor did not yield a satisfactory explanation. At this time, no reason for this occurrence is known.

Despite this problem, measurements were taken on the films. In order to minimize the "gain" in weight recorded by the instrumentation, the change in weight calculation was taken after the film had been conditioned 
and the chamber had been ramped to $300^{\circ} \mathrm{C}$. The instrument error of $0.037 \mathrm{mg}$ has been subtracted from the data. The results from this investigation are summarized in Table 3 and the raw data are given in Appendix 2. The control specimen, the "softbaked only" film, exhibited a loss in weight close to $16.5 \%$. This weight loss can be attributed to the completion of the imidization reaction occurring in the TGA chamber and the subsequent evolution of water and loss of the carrier solvent system (NMP). The weight loss in this film occurred within the first 50 minutes of the test. After this initial period, no further weight loss was observed. In comparison, the TGA for the film that had been processed through one thermal cycle showed no loss in weight. The increase in weight of $0.007 \mathrm{mg}$ was within the experimental error of the instrumentation.

It was concluded that the imidization process developed by APS yielded a completely imidized film because no loss of weight was observed in the one thermal cycle film. If the film were not fully imidized, water and NMP would have been evolved. Therefore, the completion of the imidization reaction was not a factor in this investigation. 
Table 3. Results from Thermogravimetric Analysis

\begin{tabular}{cccccc}
\hline Sample & $\begin{array}{c}\text { Intial Weight Final Weight } \\
(\mathrm{mg})\end{array}$ & $\begin{array}{c}\text { W Weight } \\
\text { Change }\end{array}$ & $\begin{array}{c}\text { Corrected Final Weight* } \\
(\mathrm{mg})\end{array}$ & $\begin{array}{c}\text { \% Weight Change } \\
\text { After Correction }\end{array}$ \\
\hline Softbake Only & 8.175 & 6.791 & -16.9 & 6.836 & -16.5 \\
1 Thermal Cycle & 5.828 & 5.873 & 0.8 & 5.835 & 0.1 \\
\hline
\end{tabular}

"Instrument error of $.038 \mathrm{mg}$ was subtracted 


\section{CHAPTER FOUR}

\section{REFRACTIVE INDEX MEASUREMENTS}

In earlier studies [12-15] densification of the polyimide film had been observed during annealing steps. If densification were occurring in PIQ, this change should be observed by refractive index measurements. An increase in the density of the material would also show an increase in the refractive index. Polyimide films were prepared as described in Chapter Two and the refractive index was measured using a prism coupler. The experimental method and results are discussed below.

\section{Refractive Index Measurements}

The refractive index of the films were measured using a prism coupler. By measuring the coupling angles at the prism and fitting them to a theoretical curve, the refractive index of the film can be obtained. For this study, a Metricon PC-2000 Prism Coupler was used. The index accuracy for this system is \pm 0.001 with an index resolution of \pm 0.0005 . The schematic of this system is shown in Figure 7. The Metricon uses a HeNe laser $(\lambda=632.8 \mathrm{~nm})$ which hits the base of the prism. Most of the beam is reflected at the base of the prism onto a photodetector. At certain mode angles which are discrete values of the incident angle $\emptyset$, photons will tunnel across the air gap into the film and enter into a guided optical propagation mode. This causes a sharp drop in the intensity of light reaching the detector. When making the measurement the film is rotated and the incident angle $\emptyset$ is varied. When two of the mode angles are found, the refractive index is 


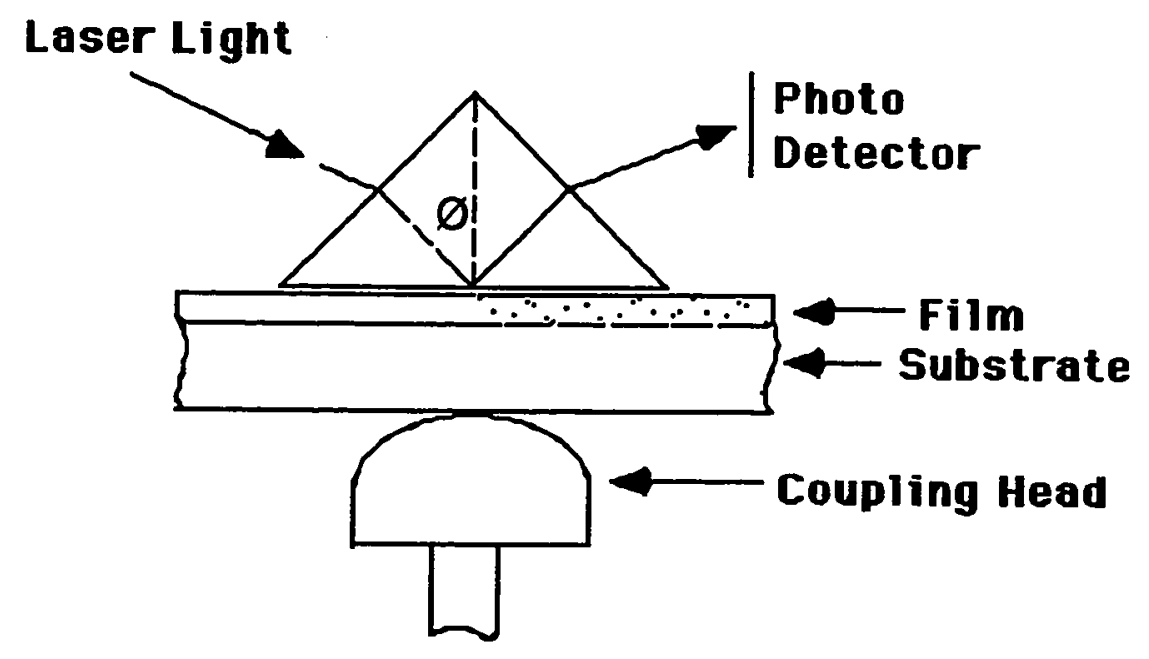

Figure 7. Schematic of a prism coupler [22]. 
calculated based on an application of Snell's law [23] which is reviewed in Appendix 3.

Because the refractive index is the ratio of the velocity of light in a vacuum to its velocity in the material, this technique should be a sensitive indication of changes occurring within the film. As the material becomes more dense, the velocity of light within the material should decrease. It would be expected that if the PIQ film were changing due to thermal cycles, the refractive index should increase. The relationship between density and refractive index is shown in Equation 1 [19].

$$
d=(M / R)\left(\left(n^{2}-1\right) /\left(n^{2}+2\right)\right)
$$

where,

$$
\begin{array}{ll}
\mathrm{d} & =\text { density } \\
\mathrm{M} & =\text { molar weight per structural unit } \\
\mathrm{R} & =\text { molar refraction } \\
\mathrm{n} & =\text { refractive index }
\end{array}
$$

The theoretical error in the application of Equation 1 is shown in Appendix 4.

Films representing a "softbaked" only film and multiple thermal cycles of one, two, three and five were prepared for this study. The films measured were approximately $3.7 \mu \mathrm{m}$ thick. Thicker films gave inconsistent results because the thicker films could support more mode angles than the detector could distinguish and analyze [19].

Each film was left mounted on the silicon wafer and the refractive index was measured in five places on the wafer: in the middle, and at positions equivalent to twelve, three, six, and nine o'clock within $3 \mathrm{~cm}$ from the edge of the wafer. 


\section{Results for Refractive Index Measurements}

The results for the refractive index measurements are shown in Figure 8. They show an increase in the refractive index from the "softbake only" film to the film that had been thermally cycled once. This is as expected because as the polyimide imidizes, it becomes more dense, the velocity of light decreases and an increase in the refractive index occurs. However, no change in the refractive index was evident after the first thermal cycle. This indicates that there were no structural changes in the film occurring due to the repeated imidizations. If thermal cycling caused densification an increase in the refractive index would be observed.

In addition to observing no change in the index, an absolute value of the refractive index was obtained. By using this technique, the refractive index for PIQ was measured to be 1.713. This is consistent with the data that has been reported by Hitachi [20].

In summary, based on the information obtained, the refractive index did not increase and PIQ did not densify during repeated thermal cycles. In addition, it was concluded that using a prism coupler to monitor a film's refractive index is a promising technique for in-situ measurements during production. The films can remain directly on the substrate and the entire wafer can be tested. Handling problems are minimal. A drawback to this technique is the film thickness limitation. 


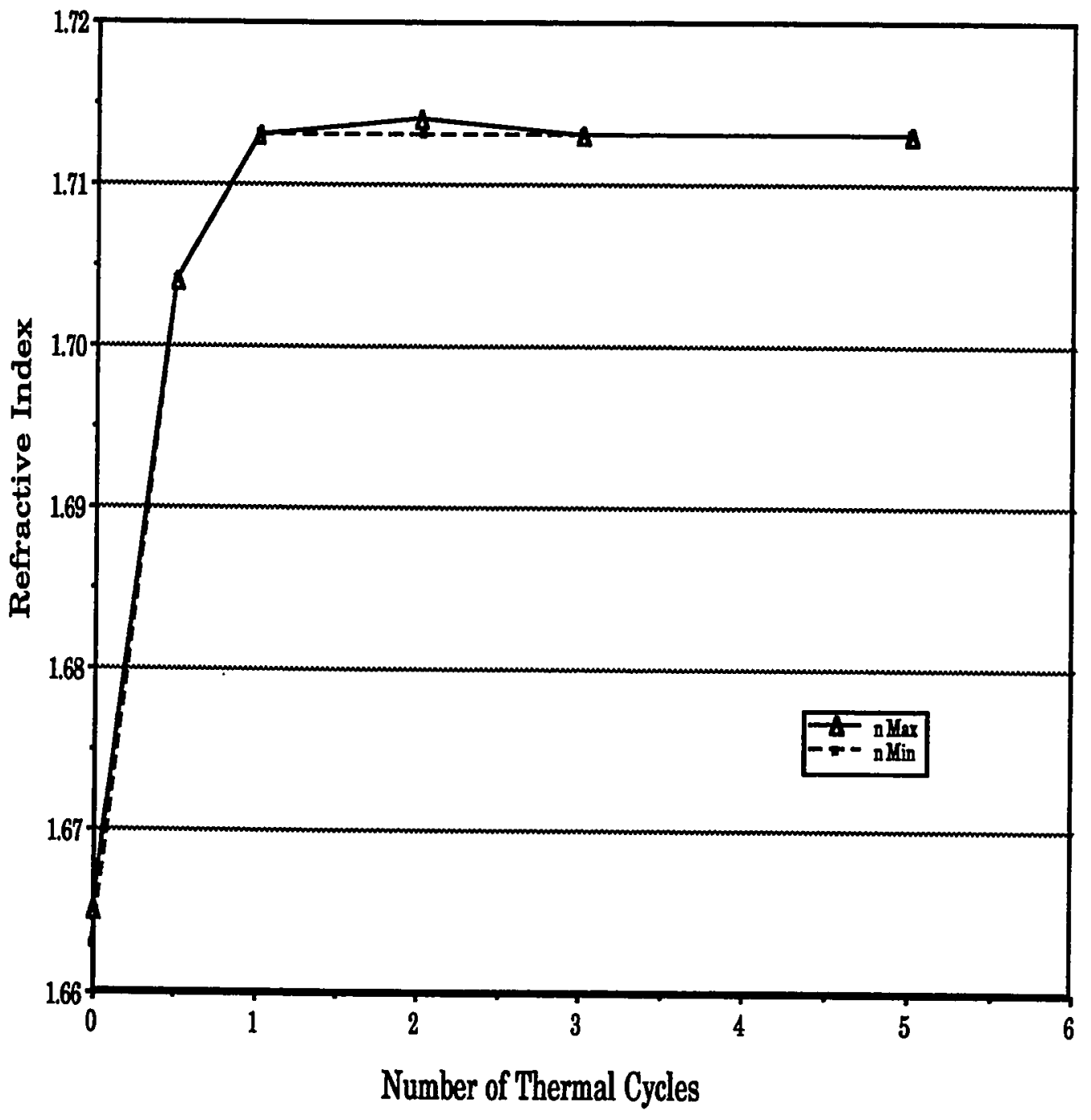

Figure 8. Change in refractive index measurements as a function of thermal cycles. 
CHAPTER FIVE

\section{CONTACT ANGLE MEASUREMENTS}

Early theories of contact angles and surface energies were established by Young [24] in 1805. The surface energy of a film is the result of the intermolecular forces which are present at the surface. Changes in the molecular structure at the surface of the material affect intermolecular forces, and as a result, will produce changes in the contact angle. Farris and Bauer [25] have shown that the orientation of the molecular chains and the film's density will affect the surface tension of the polyimide. Based on these theories, it is possible that densification of the polyimide film is not only a bulk phenomenon but also a surface phenomenon. If this is the case, by monitoring the surface tension, densification can be monitored. One method to measure surface tension is to measure the contact angle of the material. This chapter first discusses Young's equation for contact angle measurements, then the method used to measure the contact angle, and finally the results obtained.

\section{Young's Equation and Contact Angles Measurements}

A common model used to describe the contact angle is a liquid drop resting in equilibrium on a solid surface, as shown in Figure 9 [24]. The surface tensions at the three-phase contact interface are indicated as follows: $\gamma_{l v}$ is at the liquid/vapor interface, $\gamma_{\mathrm{sl}}$ is at the solid/liquid interface and $\gamma_{\mathrm{sv}}$ is at the solid/vapor interface. The Young equation relating these surface tensions to the equilibrium contact angle may be written as shown 


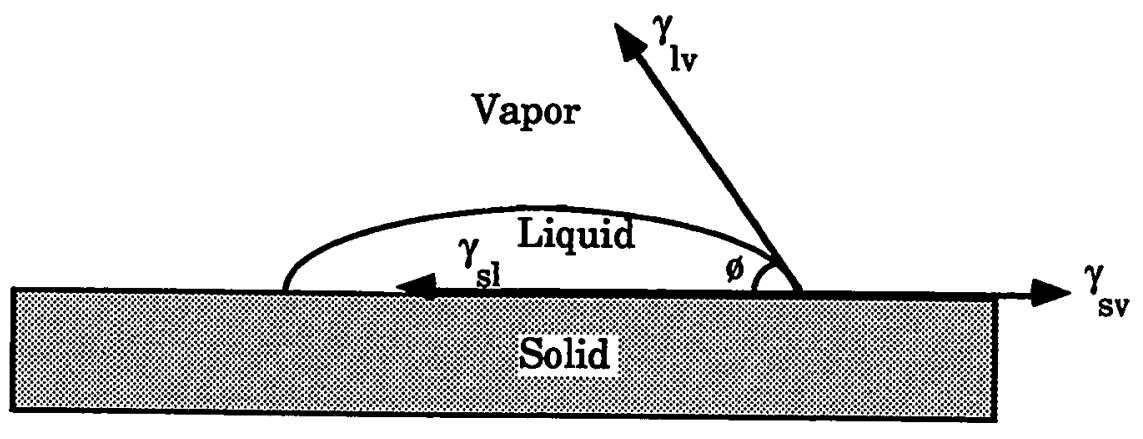

Figure 9. Equilibrium of surface tension forces acting on the line of contact of three interfaces, where $\emptyset$ is the contact angle between the liquid and solid interface. 
in Equation 2.

$$
\gamma_{\mathrm{sv}}=\gamma_{\mathrm{sl}}+\gamma_{\mathrm{lv}} \cos \emptyset
$$

The relationship between contact angle and polymer density was in previously studied [26] and is shown below in Equation 3.

$$
\left(1+\cos \emptyset_{1}\right) /\left(1+\cos \emptyset_{2}\right)=d_{1} / d_{2}
$$

$$
\text { where, } \begin{aligned}
& d_{1}=\text { surface density of polymer } 1 \\
& d_{2}=\text { surface density of polymer } 2 \\
& \emptyset_{1}=\text { contact angle measurement of polymer } 1 \\
& \emptyset_{2}=\text { contact angle measurement of polymer } 2
\end{aligned}
$$

If $d_{1}$ is greater than $d_{2}$, then $\cos \emptyset_{1}$ must be greater than $\cos \emptyset_{2}$, and $\emptyset_{1}$ less than $\emptyset_{2}$. Thus, if densification occurs in the polyimide, the contact angle decreases.

\section{Contact Angle Measurements}

For the contact angle measurements, $i 1 \mu \mathrm{m}$ films were prepared as described in Chapter Two and were thermally cycled one, five, and ten tımes. The wafers were then scribed into 2.5 by $2.5 \mathrm{~cm}$ square specimens. The contact angles measured in this study were those observed when the boundary of a sessile drop of glycerol was slowly advanced over the polyimide film and then allowed to relax. Measurements were taken using an NRL Contact Angle Goniometer, Model A-100. The schematic of this 
instrument is shown in Figure 10. Prior to measurement, a small tissue approximately 10 by $10 \mathrm{~cm}$ square was saturated with glycerol and placed in the chamber. The purpose of the tissue was to keep the chamber saturated and decrease the evaporation rate of the glycerol drop.

The specimens were placed in a convection oven and heated to $125^{\circ} \mathrm{C}$ in air for two hours before measurement. This procedure was used to condition the films and to remove any surface moisture [18]. Gloves were worn when handling the wafers, to minimize surface contamination. The film was placed into the specimen chamber. A glass syringe was used to place a small drop (diameter approximateiy $2.5 \mathrm{~mm}$ ) of glycerol on the polyimide film. The drop was illuminated from behind with a light. The lighting was adjusted so that a sharp silhouette of the drop was defined. The drop was viewed through a microscope fitted with a goniometer eyepiece. The drop was allowed to equilibrate for one hour before the first measurement was taken. Two drops were placed on each polyimide film, and three measurements were taken from each drop. The measurements were made at 45 minute intervals.

\section{Results for Contact Angle Measurements}

The results for the contact angle measurements are shown in Figure 11. The minimum and maximum contact angles measured for each thermal cycle are illustrated. The contact angles did not decrease, and it was concluded that densification does not occur in PIQ films due to thermal cycling.

This technique is limited as a production monitor. The specimen 


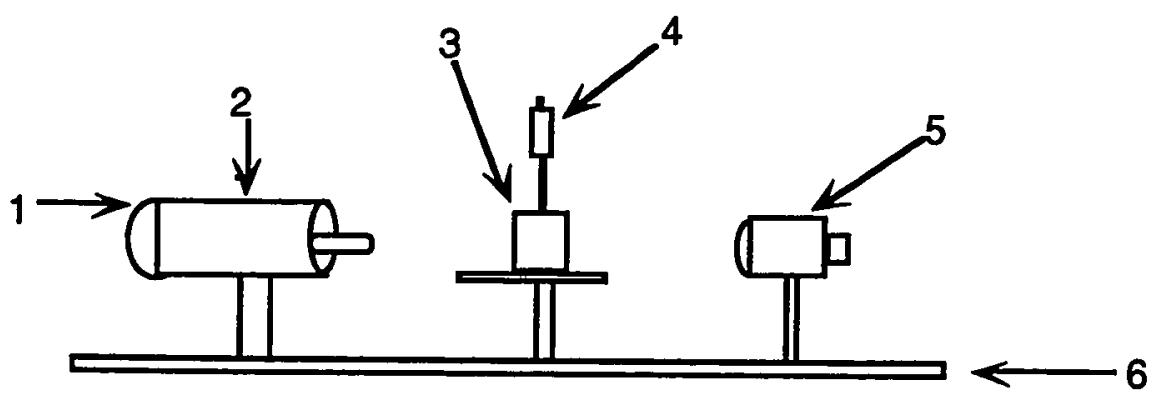

1 Goniometer scale

2 Microscope assembly

3 Specimen stage/chamber

4 Syringe

5 Illuminator

6 Optical bench

Figure 10. Schematic of Contact Angle Goniometer [27]. 


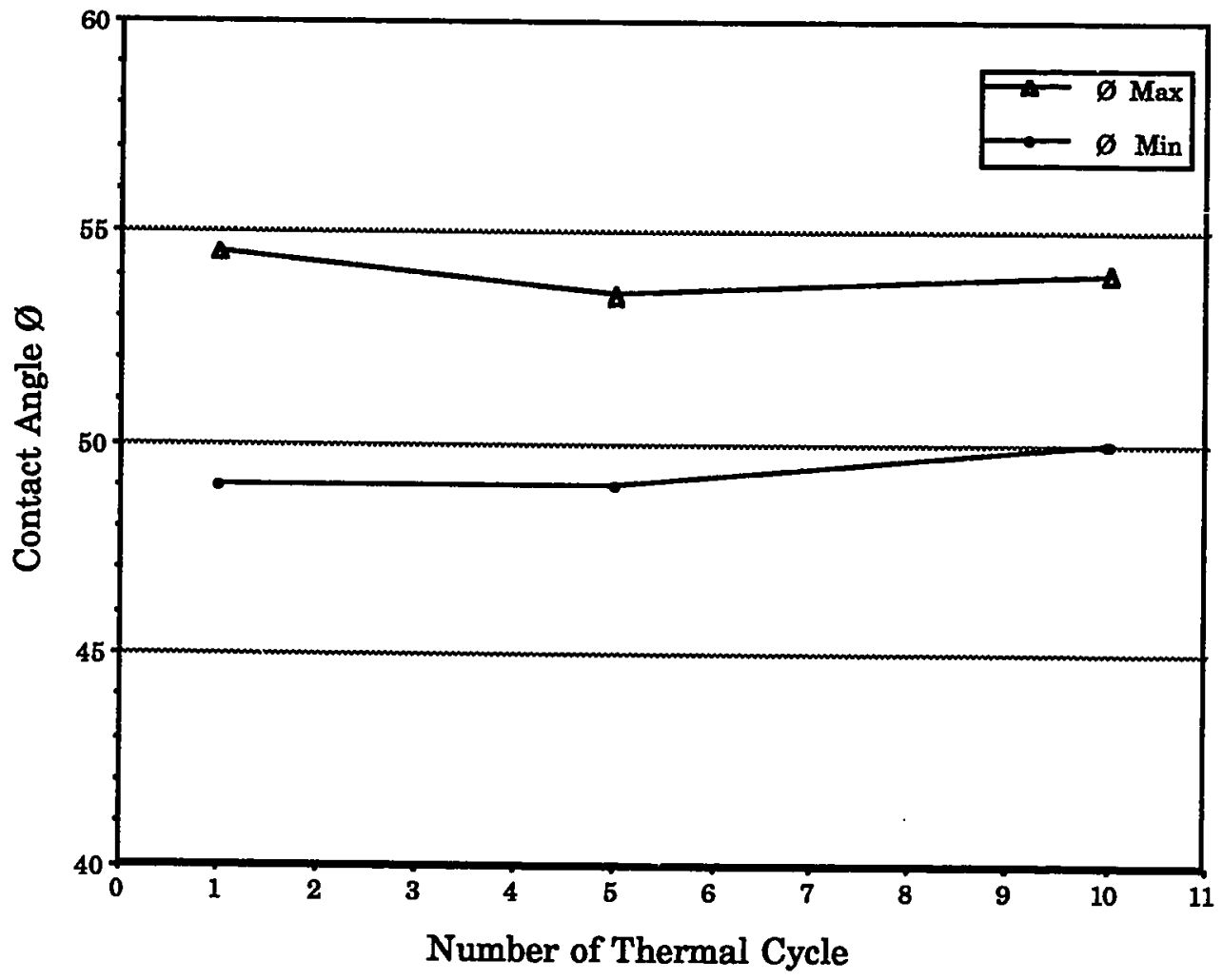

Figure 11. Change in contact angle measurements as a function of thermal cycles. 
chamber was too small and wafers needed to be scribed. Because of the limited chamber size, production wafers of $125 \mathrm{~mm}$ cannot be studied. A new chamber would be required to use this method in production. 


\section{CHAPTER SIX \\ DYNAMIC MECHANICAL ANALYSIS}

In previous studies with PMDA-ODA polyimide, the research indicated that a change in the mechanical properties of the material could occur with thermal cycling [15]. This change in a film can be characterized using Dynamic Mechanical Analysis (DMA). This method, the results and the problems of this technique are discussed below.

\section{Dynamic Mechanical Analysis}

Dynamic Mechanical Analysis (DMA) is a technique used to study the chemical and physical structure of polymers. This technique measures the response of a material to a periodic stress. The results from DMA separate the viscoelasticity of a material into two components of modulus $\left(\mathrm{E}^{*}\right)$ : a real part, which is the elastic modulus ( $\left.E^{\prime}\right)$, and an imaginary part, which is the damping or viscous component ( $\left.E^{\prime \prime}\right)$.

$$
\mathrm{E}^{*}=\mathrm{E}^{\prime}+\mathrm{i} \mathrm{E}^{n}
$$

The angle which reflects the time lag between the applied stress and strain is $\partial$, and it is defined by a ratio called the dissipation factor:

$$
\tan \partial=E^{n} / E^{\prime}
$$

The $\tan \partial$ is a damping term and is a measure of the ratio of energy 
dissipated as heat to the maximum energy stored in the material during one cycle of oscillation. A low $\tan \partial$ material converts little of the applied energy into heat. A high tan $\partial$ material dissipates most of the applied energy into heat. Both PMDA-ODA and PIQ polyimides are considered to be low $\tan \partial$ materials $(\tan \partial<2.0)[28]$.

In addition to modulus and tan $\partial$ information, DMA is often used to determine the glass transition $\left(\mathrm{T}_{\mathrm{g}}\right)$ and secondary transitions of the material. This information is obtained when the material is subjected to a periodic stress as a function of temperature. At the secondary transition temperatures the elastic modulus decreases and at the glass transition temperature, the elastic modulus approaches zero. If repeated imidization cycles of the polyimide film caused chemical changes such as modifications of the backbone structure or side groups, a shift would occur in the $\mathbf{T}_{\mathbf{g}}$. Also, if repeated cycling caused densification in the film, the tan $\partial$ of the material would change. This would be expected because an increase in density would result in a decrease of free volume. As the free volume decreased, the molecular mobility would be more restricted, and the tan $\partial$ in the material would decrease.

Films were prepared and were removed from the substrate as described in Chapter Two. The films made represented one, three, and five thermal cycles. Again, as with the earlier TGA tests, handling the free films was difficult. Care was taken to prepare the specimens for DMA measurement since accuracy and reproducibility of the test data were found to be a function of correctly mounting the specinens. Although many attempts were made to establish a procedure to test these thin films, 
problems were encountered. These problems will be discussed in greater detail later in this chapter.

The films were tested at a fixed frequency of $0.5 \mathrm{~Hz}$ and examined over a temperature range of $-25^{\circ} \mathrm{C}$ to $450^{\circ} \mathrm{C}$. The ramp rate of the chamber was $4^{\circ} \mathrm{C} /$ minute.

\section{Results for DMA}

Using dynamic mechanical analysis the $T_{g}$ and secondary transitions were monitored. In addition, the storage modulus E', the loss modulus $E^{\prime \prime}$ and $\tan \partial$ were also calculated.

Because of fixturing limitations with the equipment and problems with handling the thin films, accurate and reproducible storage and loss modulus values could not be obtained. Many trials were run, without any success.

Despite these problems, glass transition temperature values and tan $\partial$ values were obtained. The effect of thermal cycling on the $T_{g}$ is shown in Figure 12. The data indicate that the glass transition temperature does not change and that thermal cycling does not have an effect on the polyimide. If densification were occurring, the molecular structure would become stiffer, and an increase in the $\mathrm{T}_{\mathrm{g}}$ should be observed. The data from this study show that the PIQ film has a $\mathrm{T}_{\mathrm{g}}$ of $343^{\circ} \mathrm{C}$. Hitachi has reported a $\mathrm{T}_{\mathrm{g}}$ of $354^{\circ} \mathrm{C}[10]$. The difference in these values can be attributed to the test frequency used since Hitachi used $10 \mathrm{~Hz}$, and this analysis used $0.5 \mathrm{~Hz}$. For most polymers the $\mathrm{T}_{\mathrm{g}}$ increases approximately $7^{\circ} \mathrm{C}$ for a factor of ten increase in frequency [29].

Despite the problems with obtaining reproducible modulus 


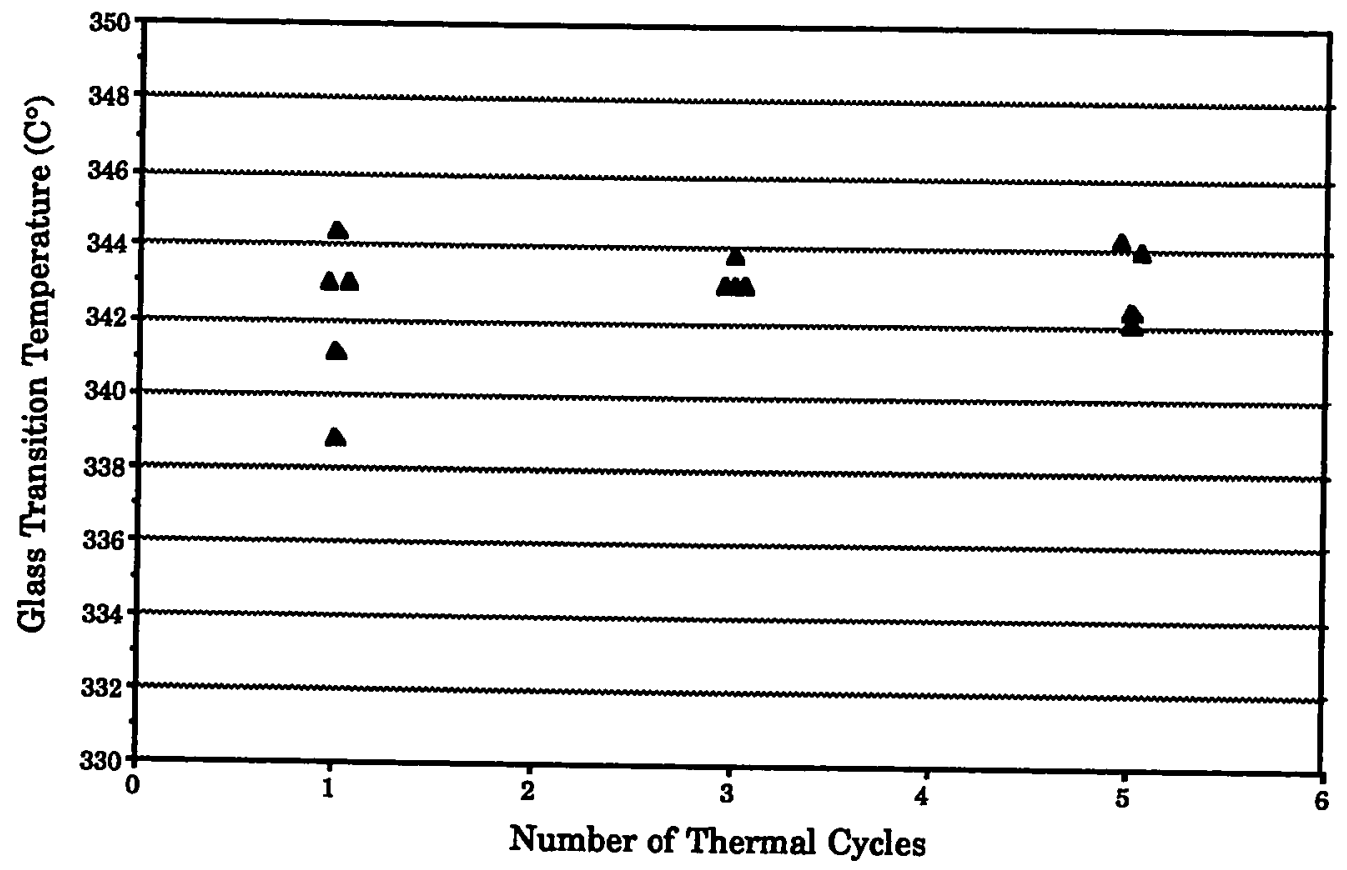

Figure 12. Glass transition data from dynamic mechanical analysis. 
information, the information for the $\tan \partial$ was surprisingly consistent. One hypothesis is that because the $\tan \partial$ is actually a ratio, any procedural errors that occurred when obtaining the loss and storage modulus were canceled out. Figure 13 shows the change in $\tan \partial$ as a function of thermal cycles. There appears to be no differences among the films. If the films were changing due to densification, an increase in the tan $\partial$ would have been observed. No shift is evident.

In summary, because of handling and fixturing limitations, an absolute storage value could not be obtained nor could values be compared. However, both glass transition temperatures and $\tan \partial$ values of the PIQ could be obtained. Based on these values, there does not appear to be any changes in the mechanical properties of the polyimide film due to thermal cycling. 


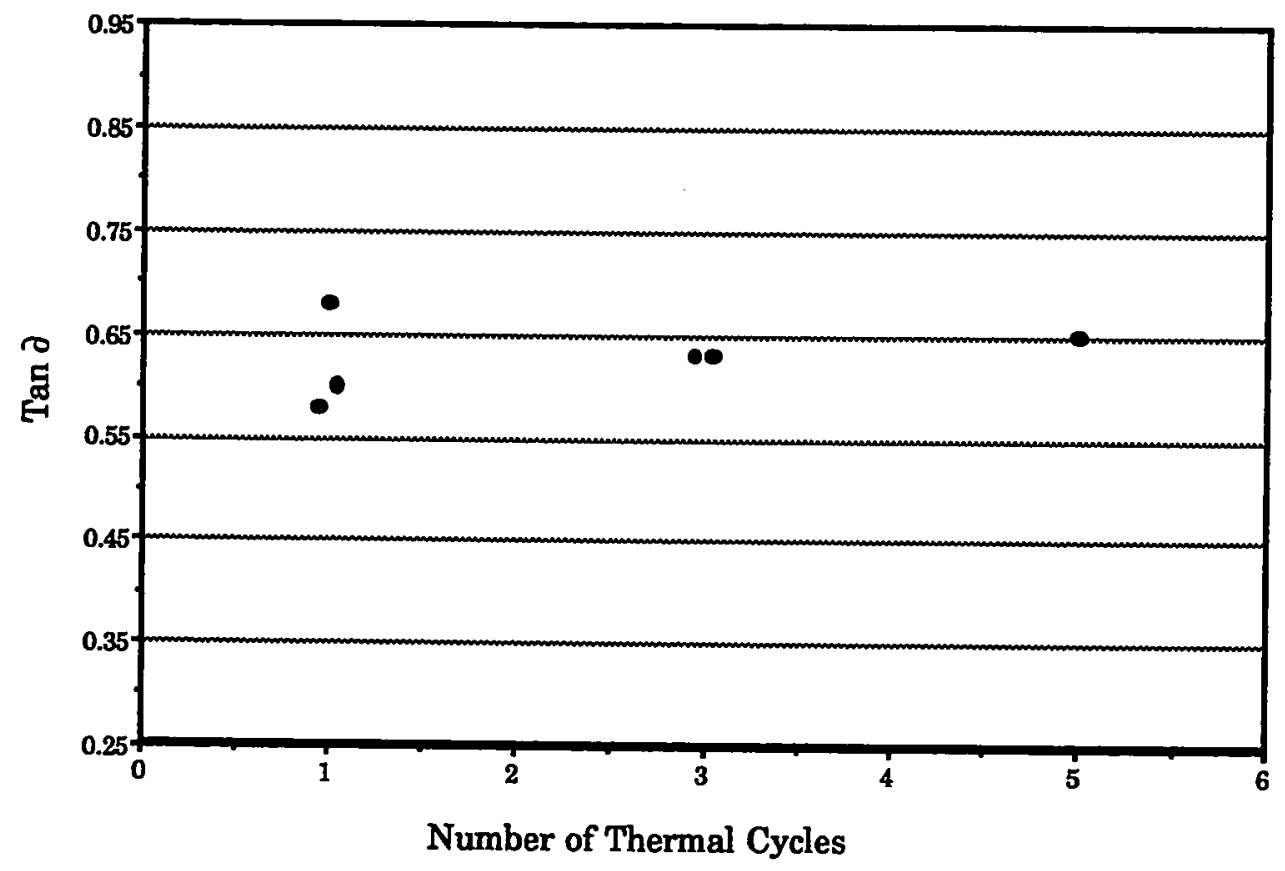

Figure 13. Tan $\partial$ data from dynamic mechanical analysis. 


\section{CHAPTER SEVEN \\ SUMMARY AND CONCLUSIONS}

\section{Review of the Problem}

The question which was addressed by this thesis was whether densification occurred in PIQ polyimide films due to repeated thermal cycling. Previous research on PMDA-ODA polyimide systems had observed densification and an increase in the modulus of the film. If similar behavior occurred in PIQ, these changes in the film could effect the film's performance and reliability, especially if the polyimide were to be used in a multilayer application.

\section{Discussion of the Findings}

Based on the results from this research, it appears that the process used by Advanced Packaging Systems yields an imidized polyimide film, and that the film does not change when subjected to repeated thermal cycles.

The evidence from the prism coupler study showed no increase in the film's refractive index after thermal cycling, indicating that densification is not occurring.

The data from the contact angle measurements showed no change in the angles measured as a function of thermal cycling. However, after reviewing the technique used in this study, the author is concerned about using this method as a means to monitor densification. It is possible that this technique does not have the sensitivity required to measure surface changes as a result of densification.

The findings from the DMA showed no shifts in the glass transition 
temperature or in the $\tan \partial$. This information leads to the conclusion that the PIQ system does not change after thermal cycling.

After analyzing the structure of PIQ, these results are not surprising. $\mathrm{PIQ}$ is a random copolymer and with the quinazolinedione ring, densification is difficult. Once the rings are formed, the system is constrained and bonding between the polymer chains is limited. Despite the Hitachi Chemicals scientists' hypothesis of the potential ladder structure, once the PIQ film was fully imidized, there was no evidence to indicate any change was taking place in the film.

In addition to these results, the use of a prism coupler to monitor changes in the film is a promising technique. Measurements can be made on the wafer, with no handling or wafer size constraints.

\section{Conclusions}

The findings from this research is that PIQ polyimide is thermally stable and is an appropriate material for multilayer applications. Densification does not occur in PIQ and no shifts in the mechanical performance occur due to thermal cycling.

One possible conclusion from this study is that polymer systems with a nonlinear orientation, such as PIQ, may be less prone to densification than those systems with a linear orientation. An analysis of the molecular orientation of the polyimide when initially selecting systems for multilayer application may offer some clues as to the resistance of the polymer to densification. 


\section{Recommendations for Future Action and Research}

The evaluation methods used for this research included refractive index measurements and dynamic mechanical analysis. Although PMDA-ODA was being compared indirectly with the PIQ system, it was not tested in this study. A side by side comparative study on PMDA-ODA using these same test methods is recommended. This would both provide a direct comparison between the two materials and validate the tests used in this study. Further testing would also help determine if contact angle studies have any value in determining densification.

In addition, further research is needed for correlating changes in the film behavior with product performance. For those materials that densify with thermal cycling, how does densification impact the product? Also, does densification continue with repeated cycling or is there a number of cycles after which the film becomes stable?

As previously stated, there was some difficulty in handling and measuring the thin films. Most of the experience at Raychem, where the TGA and DMA tests were conducted, is with thicker and larger films. Because of the shortcomings of the DMA, absolute values of the storage modulus could not be obtained or compared to values cited in previous work. However, if absolute values were sought, more work in handling, fixturing and measuring the thin films would be required. 


\section{REFERENCES}

[1] Lee, Y.K. and M. Fryd. 1987. Polyimides. In The Chemistry of the Semiconductor Industry, ed. S. J. Moss and A. Ledwith, 282-291. New York: Chapman and Hall.

[2] Wilson, Arthur M. 1984. Use of polyimides in VSLI fabrication. In Polyimides. Synthesis, Characterization, and Applications, ed. K.L. Mittal, 715-733. New York: Plenum Press.

[3] Chevrier, J. C. and E. L. Yuan. 1986. Polyimide dielectrics of high density and high speed packaging. In Proceedings of the Sixth Annual International Electronic Packaging_Conference, San Diego: International Electronic Packaging Society, 285293.

[4] Rothman, L. B. 1980. Properties of thin polyimide films. J. Electrochem Soc. Solid-State Science and Technology 127 : 2216-2220.

[5] Wilson, Arthur M. 1981. Polyimide insulators for multilevel interconnections. Thin Solid Films 83: 145-163.

[6] Jensen, Ronald J., John P. Cummings, and Harshadrai Vora. 1984. Copper/polyimide materials system for high performance packaging. IEEE Transactions on Components. Hybrids and Manufacturing Technology vol. CHMT-7 : 384393.

[7] Keyes, Robert W., Warren D. Grobman, and Shukla Kapur. 1989. Thin film packaging. In Microelectronics Packaging Handbook, ed. Rao R. Tummala and Eugene J. Rymaszewski, 692. New York : Van Nostrand Reinhold.

[8] Advanced Packaging Systems. 1990. Product Bulletin A Revision 3, San Jose,California.

[9] J. C. Chevrier and E. L. Yuan, op. cit. 285. 
[10] Suzuki, Hiroshi, scientist at Hitachi Chemical Company. 1990. Interview by author, 29 August, San Jose, California.

[11] Makino, D. (No date given). Technical Notes on the Products for Semiconductor Devices. Hitachi Chemical Company.

[12] Russell, Thomas. 1984. A small-angle $\mathrm{x}$ ray scattering study of an aromatic polyimide. Journal of Polymer Science 22 : 11051117.

[13] Isoda, Satoru, Hiromichi Shimada, Masakatsu Kotchi, and Hirotaro Kambe. 1981. Molecular agregation of solid aromatic polymers. Journal of Polymer Science 19: 1293-1312.

[14] Takahashi, Nobuyuki, Do Y. Yoon, and William Parrish. 1984. Molecular order in condensed states of semiflexible poly(amic acid) and polyimide. Macromolecules 17: 2583-2588.

[15] Feger, Claudius. 1989. Curing of polyimides. Polymer Engineering and Science 29: $347-351$.

[16] Lai, Juey H., Richard B. Douglas, and Kevin Donohoe. 1986. Characterization and processing of polyimide thin films for microelectronic application. Ind. Eng. Chem. Prod Res. Dev. 25: 38-40.

[17] Shuckert, Craig C., G. B. Fox, and B. T. Merriman. 1986. The evolution of packaging dielectrics. In Proceedings of the Second du Pont Symposium for High Density Interconnect Technology, 107-120.

[18] Keeley, Al, project manager at Advanced Packaging Systems. 1986. Interview by author, 8 July, San Jose, California.

[19] Horsma, David, development manager at Advanced Packaging Systems. 1990. Interview by author, 19 January, San Jose, California. 
[20] Hitachi Chemical Company. (No date given). Hitachi HeatResistant Fine Polvmer. PIQ. Number Ay-E015D.

[21] Cassidy, Patrick E. 1980. Thermally stable polymers. New York: Marcel Dekker, Inc.

[22] Ulrich, R. and R. Torge. 1973. Measurement of thin film parameters with a prism coupler. Applied Optics 12: 29012908.

[23] Jarvis, Bruce, physicist at Advanced Packaging Systems. 1990. Interview by author, 19 January, San Jose, California.

[24] Young, Thomas. 1805. Phil. Trans. Roval Soc. Vol. 95, No. 65 London.

[25] Farris, R. J. and C. L. Bauer. 1988. A self delamination method of measuring the surface energy of adhesion of coatings. $\mathcal{L}$ Adhesion. 26: 293-300.

[26] Johnson, R. E. and H. Dettre. 1969. Wettability and contact angles. In Surface and Colloid Science, ed. E. Matijevic, 133-134. New York: Interscience.

[27] Rame-Hart Bulletin for Model A-100 Contact Angle Goniometer. (No date given). (Photocopied).

[28] E.I. du Pont de Nemours and Co. (No date given). Technical Notes for DMA 983. pp. 4.64 .

[29] Nielsen, Lawrence E. 1974. Mechanical properties of polymers and composites. New York: Marcel Dekker, Inc. 


\section{BIBLIOGRAPHY}

Billmeyer, Fred W. Textbook of Polymer Science. New York: John Wiley and Sons, 1984.

Meeten, G.H., ed. Qptical Properties of Polymers. New York: Elsevier Applied Science Publishers, 1986.

Reichmanis, Elsa and Cletus W. Wilkins, Jr., "Chemistry of Microelectronic Polymers." In Microelectronic Polymers, ed. Maung S. Htoo, New York: Marcel Dekker Inc., 1989.

Saenger, Katherine and Ho-Ming Tong, "Laser Interferometric Measurement of Polymer Thin Film Thickness Changes During Processing." Journal of Applied Polymer Science 33 (1987): 17771784 .

Van Krevelen, D.W. Properties of Polymers: Their Estimation and Correlation with Chemical Structure. Amsterdam: Elsevier Scientific Publishing Company, 1976.

Wachsman, Eric and Curtis Frank, "Effect of Cure History on the Morpholgy of Polyimide: Fluorescence spectroscopy as a method for determining the degree of cure," Polymer 29 (1988): 1191-1197.

Wendlandt, W. W. and P. K. Gallagher, "Instrumentation." In Thermal Characterization of Polymeric Materials, ed., Edith A. Turi, New York: Academic Press, 1981.

Wunderlich, Bernard, "The Basis of Thermal Analysis." In Thermal Characterization of Polymeric Materials, ed., Edith A. Turi, New York: Academic Press, 1981. 


\section{APPENDIX 1}

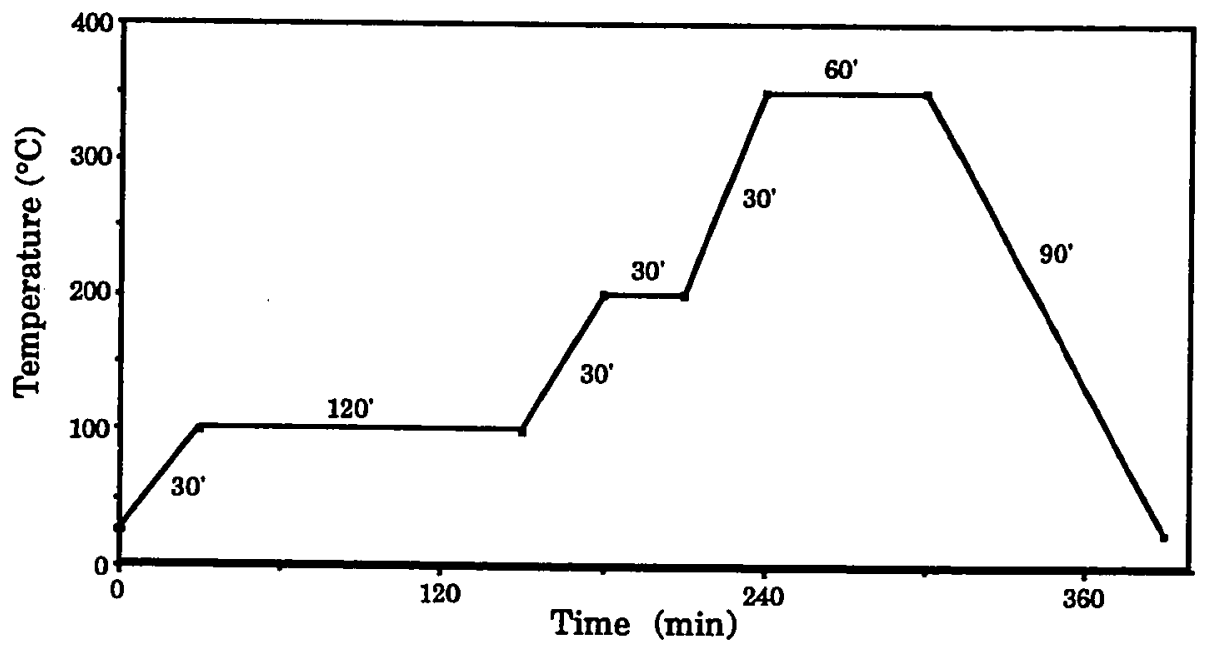

Figure 14. Hitachi Chemical Company's recommended imidization process for PIQ in a convection oven [20]. 


\section{APPENDIX 2}

TGA results for empty pan

PERKIN-ELMER

7 Series Thermal Analysis Systea

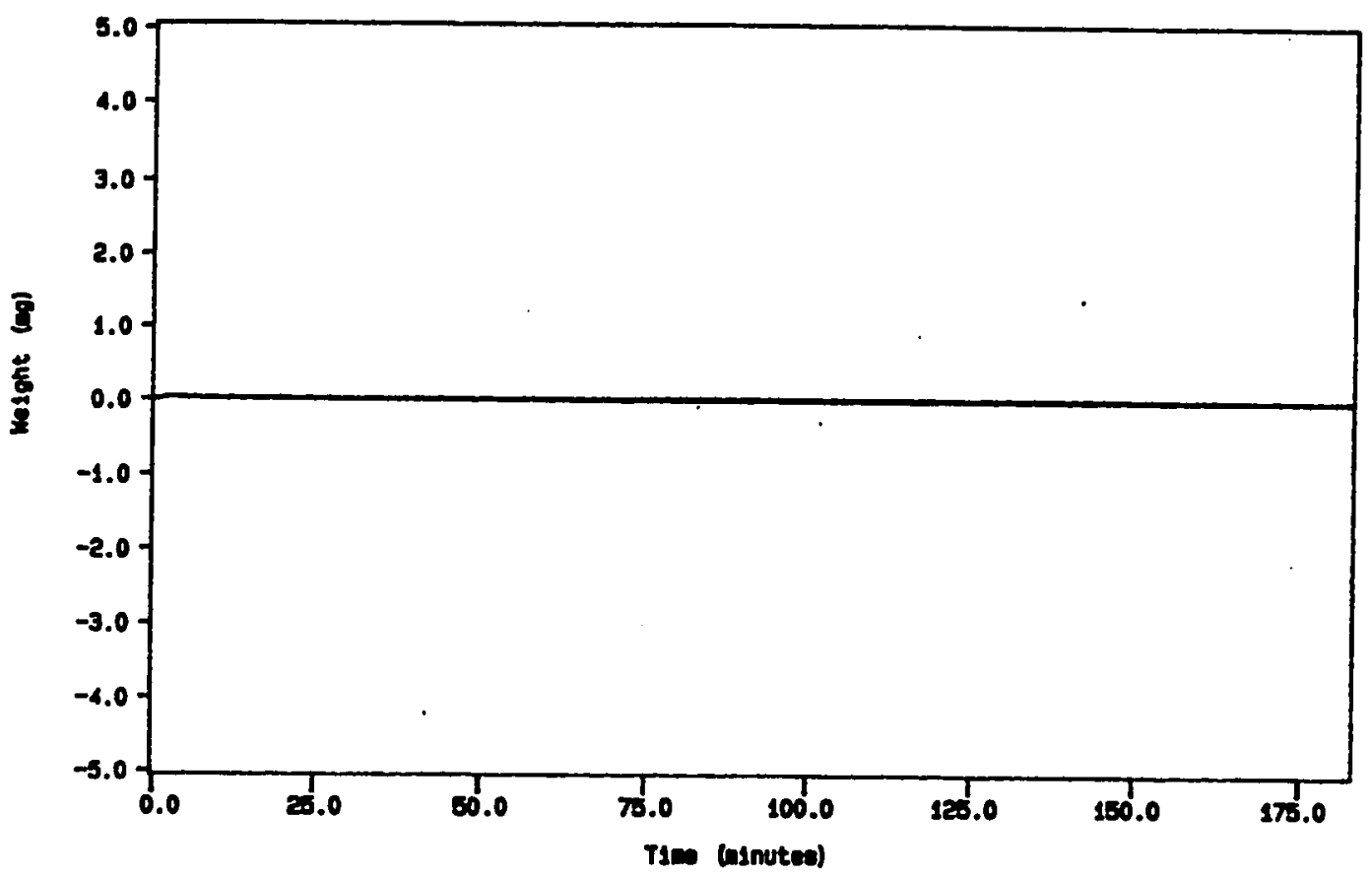




\section{APPENDIX 2 (CONTINUED) \\ TGA results for polyimide film "soft baked" only}

\section{PERKIN-ELMER}

7 Series Thermal Analysis Systen

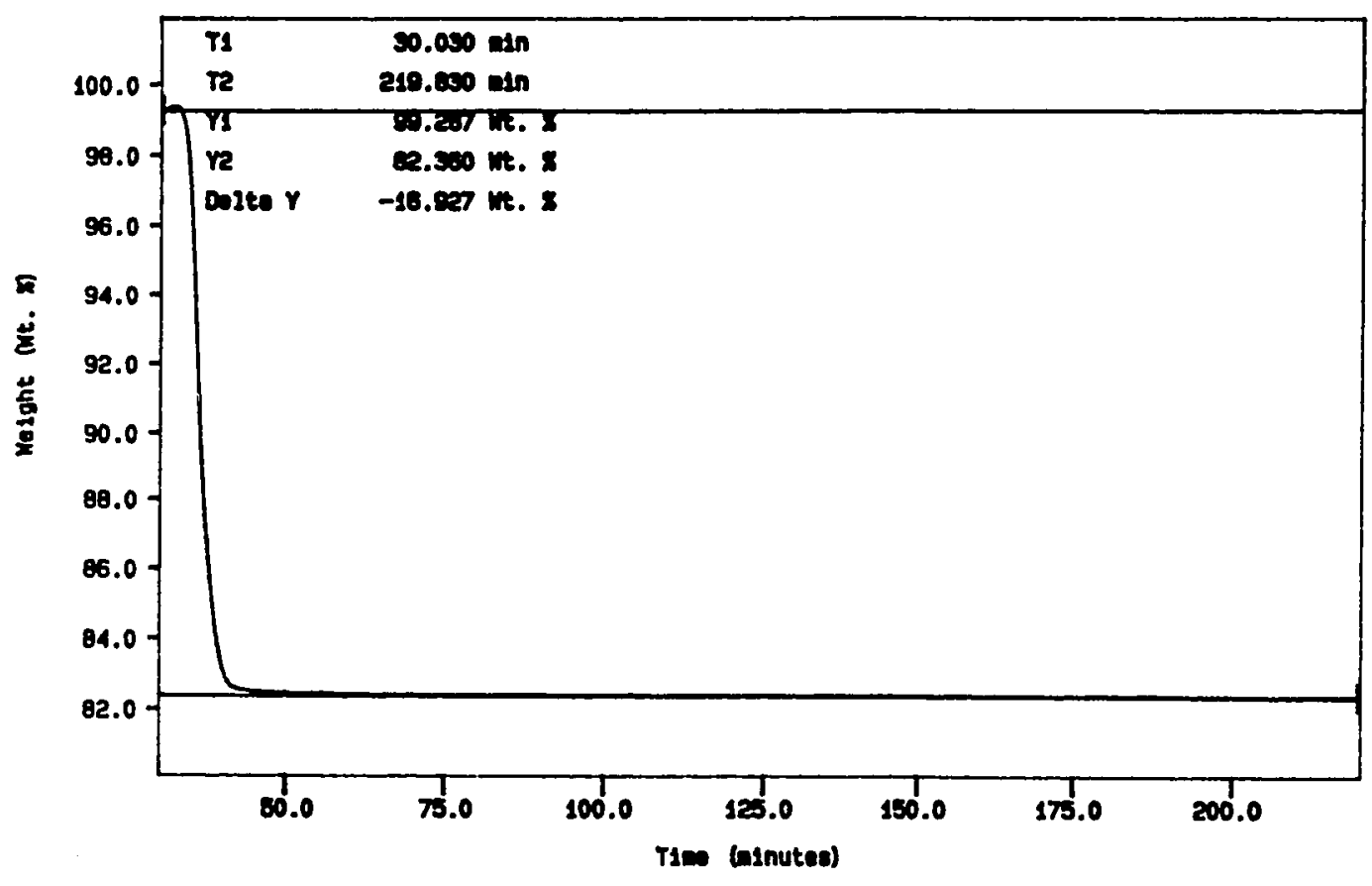




\title{
APPENDIX 2 (CONTINUED)
}

TGA results for polyimide film one thermal cycle

\author{
PERKIN-ELMER
}

7 Series Thermal Analysis System

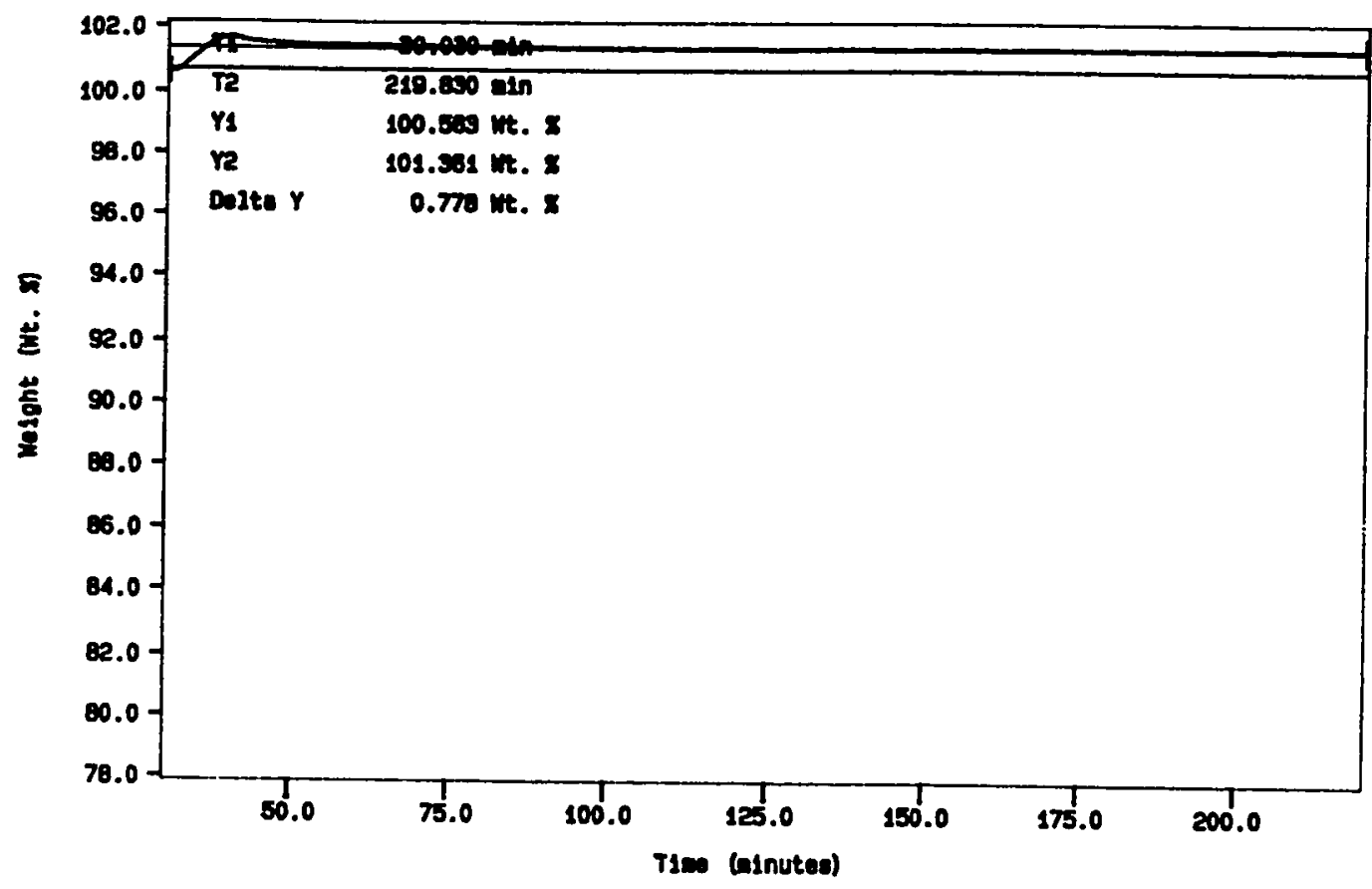


APPENDIX 3

Snell's Law

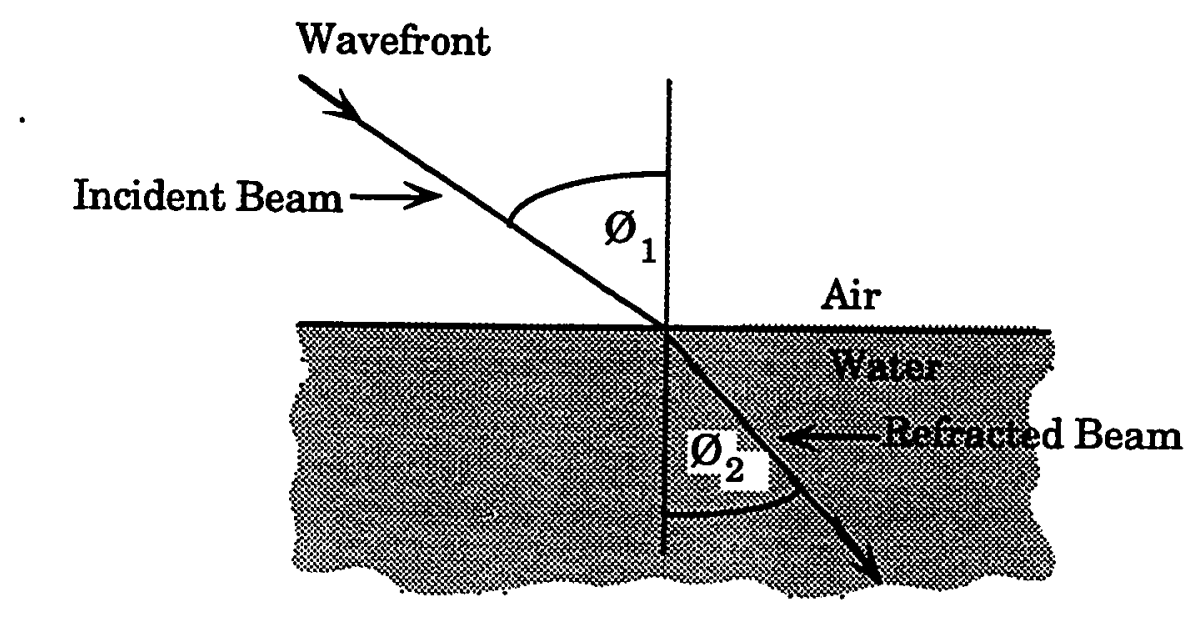

Figure 15. Illustration of Snell's Law.

The angles of incidence $\emptyset_{1}$ and of refraction $\emptyset_{2}$ are measured between the normal to the surface and the appropriate ray as shown in Figure 15. The index of refraction or Snell's Law is:

$$
\sin \emptyset_{1} / \sin \emptyset_{2}=n_{21}
$$

where $n_{21}$ is called the index of refraction of medium 2 to medium 1. 


\section{APPENDIX 4}

The theoretical error in the application of Equation 1 from Chapter Four is shown below. This calculation illustrates the error in the density measurement as a function of the error in the refractive index measurement.

$$
d=(M / R)\left(\left(n^{2}-1\right) /\left(n^{2}+2\right)\right)
$$

where,

$$
\begin{array}{ll}
\mathrm{d} & =\text { density } \\
\mathrm{M} & =\text { molar weight per structural unit } \\
\mathbf{R} & =\text { molar refraction } \\
\mathrm{n} & =\text { refractive index }
\end{array}
$$

Differentiating both sides with respect to $\mathrm{n}$,

$$
\begin{aligned}
& \frac{\Delta d}{\Delta \mathrm{n}}=(\mathrm{M} / \mathrm{R}) \quad \frac{\left(\mathrm{n}^{2}+2\right) 2 \mathrm{n}-\left(\mathrm{n}^{2}-1\right)(2 \mathrm{n})}{\left(\mathrm{n}^{2}+2\right)^{2}} \\
& \Delta \mathrm{d}=(\mathrm{M} / \mathrm{R}) \quad \frac{6 \mathrm{n}}{\left(\mathrm{n}^{2}+2\right)^{2}} \Delta \mathrm{n}
\end{aligned}
$$

In this investigation, the refractive index of PIQ was found to be 1.713. $M / R$ is a constant and equal to 3.63 for PIQ, applying Equation $1 b$,

$$
\Delta d=1.53 \Delta n
$$

The error in the density measurement $(\Delta d)$, as a function of the error in the refractive index measurement $(\Delta \mathrm{n})$ is shown in Equation 1c. Since the error in the $\Delta \mathrm{n}$ measurement is \pm 0.0005 , the density error is approximately \pm 0.0008 grams $/$ cc. 